\title{
LOS BATANES HIDRÁULICOS DE LA CUENCA DEL GUADALQUIVIR A FINES DE LA EDAD MEDIA. EXPLOTACIÓN Y EQUIPAMIENTO TÉCNICO ${ }^{1}$
}

\author{
THE WATER-POWERED FULLING MILLS OF THE GUADALQUIVIR BASIN \\ IN THE LATE MIDDLE AGES. THEIR OPERATION AND TECHNICAL EQUIPMENT
}

\author{
RICARDO CÓRDOBA DE LA LLAVE \\ Universidad de Córdoba
}

\begin{abstract}
Resumen: El presente trabajo tiene por objeto el análisis tecnológico de los batanes hidráulicos que funcionaron en la cuenca del Guadalquivir a fines de la Edad Media. Tras repasar brevemente el proceso de abatanado de los paños de lana, el artículo se centra en la discusión acerca del origen y difusión del batán hidráulico en Europa y en la Península Ibérica. A continuación se describen los rasgos de su arquitectura y se exponen los lugares donde se ubicaron en los ríos más importantes de la cuenca. El capítulo principal es el dedicado a estudiar su funcionamiento, analizando los sistemas empleados para el aprovechamiento de la energía hidráulica (presas, canales, ruedas hidráulicas y árbol de levas) y los diversos componentes o piezas de la maquinaria (castillo, astiles, mazos, pila). Una breve reflexión sobre la pervivencia a lo largo de los siglos de la tecnología utilizada en los batanes cierra el trabajo.
\end{abstract}

Palabras clave: batanes; hidráulica; industria textil; tecnología; mecánica.

\begin{abstract}
This paper aims to be a technological analysis of the waterpowered fulling mills working in the Guadalquivir basin in the Late Middle Ages. After briefly reviewing the process of fulling woollen cloth, this paper focuses on the discussion about the origin and spread of fulling mills in Europe and the Iberian Peninsula. It then describes the features of their architecture and it looks at the places where they were located on the most important rivers of the basin. The main chapter is devoted to studying how they worked, analyzing the systems used for making better use of water-power (dams, channels, vertical water wheels and camshafts) and the various components or pieces of machinery (castle, beams, triphammers, stack). The study ends with a brief reflection on the technology used in the mills.
\end{abstract}

Keywords: fulling mills; water power; textile industry; technology; mechanics.

\footnotetext{
${ }^{1}$ Abreviaturas utilizadas: ADM $=$ Archivo Ducal de Medinaceli; AHJT $=$ Archivo Histórico Judicial de Toledo; AHN = Archivo Histórico Nacional; AHPCO = Archivo Histórico Provincial de Córdoba; AHPJA = Archivo Histórico Provincial de Jaén; AHPSE = Archivo Histórico Provincial de Sevilla; $\mathrm{AMCO}=$ Archivo Municipal de Córdoba; $\mathrm{ARChGr}=$ Archivo de la Real Chancillería de Granada; LAC = Libro de Actas Capitulares; LO = Libro de Ordenanzas; PNCO = Sección de Protocolos Notariales de Córdoba; PNCS = Sección de Protocolos Notariales de Castro del Río; PNJA = Sección de Protocolos Notariales de Jaén; PNMO = Sección de Protocolos Notariales de Montoro; PNSE = Sección de Protocolos Notariales de Sevilla
} 


\section{SUMARIO}

1. El abatanado de los paños.- 2. Los batanes hidráulicos.- 2.1. Origen y expansión del batán hidráulico.- 2.2. Ubicación y explotación de los batanes.- 2.3. Piezas y componentes de la maquinaria.- 3. Bibliografía citada.

El batán es un ingenio mecánico compuesto por una rueda hidráulica vertical que, movida por la fuerza de una corriente de agua, hace dar vueltas a un eje horizontal en el que va colocada una serie de álabes o tablas de madera. Dichos álabes inciden alternativamente, en su movimiento de rotación, sobre unas piezas de madera que enganchan, elevan y dejan caer por su propio peso unos grandes mazos que golpean rítmicamente el paño de lana, previamente introducido en una pila con mezcla de agua y greda. Parece que los términos batán, referido a la máquina utilizada para realizar la operación, y batanar y abatanado, referidos a la operación misma, proceden del vocablo árabe battana que, con el significado de "golpear", también habría sido usado en al-Andalus y el mundo islámico medieval².

En el sur de la Península Ibérica, y más concretamente en la cuenca media del Guadalquivir, la existencia de batanes hidráulicos está bien documentada desde las décadas finales del período medieval y se mantuvieron en uso hasta finales del siglo XIX. El río Guadalquivir fue el gran protagonista de la ubicación de estas instalaciones, que también se situaron en algunos de sus afluentes más caudalosos, como el Guadajoz o el Guadaira, por depender para su funcionamiento de corrientes con elevado caudal. En su interior, y en dependencias anejas al propio batán, se realizó el abatanado de los paños de lana, un proceso imprescindible dentro de las operaciones seguidas para la fabricación del tejido de lana y que se llevó a cabo en términos muy similares a como se venía haciendo desde época clásica, salvo por el uso de los mazos mecánicos. Debido a que el auténtico sentido de los batanes venía dado por la realización de las operaciones que acompañaban al abatanado o golpeo del paño propiamente dicho, parece conveniente repasar primero, brevemente, los principales rasgos que dicho proceso presentaba en época bajomedieval, para a continuación centrarnos en los auténticos protagonistas del mismo, los batanes hidráulicos.

\section{EL ABATANADO DE LOS PAÑOS}

Durante la época romana y la Alta Edad Media el abatanado de los paños fue realizado exclusivamente de manera manual, depositando el paño en grandes cubas de madera (las llamadas pilae fullonicae) donde, en una mezcla de orina, greda $\mathrm{u}$ otras sustancias, era pisado repetidamente, como se hace con la uva para extraer el mosto, hasta concluir el tratamiento ${ }^{3}$. Sin embargo, en algún momento de la Edad Media, comenzó a hacerse un uso generalizado del abatanado mecánico de los paños gracias a la invención, o quizás a la difusión, del ingenio movido por energía hidráulica que desde entonces hasta el siglo XX ha sido conocido por el término de batán. A partir de ese momento, los batanes hidráulicos se fueron extendiendo por todos los grandes ríos europeos, convirtiéndose en uno de los grandes protagonistas, junto con

\footnotetext{
${ }^{2}$ M. Argemí et al., Glosario, p. 167.

${ }^{3}$ Como se aprecia en el bajorrelieve romano de la tumba de un batanero conservado en el Museo francés de Sens y reproducido por K.D. White, Greek, p. 35, entre otros autores. Para la descripción del proceso, A. Uscatescu, Fvllonicae, pp. 25-89; A. Uscatescu, En torno, pp. 203-220; y C. Alfaro, Tejido, pp. 225-227.
} 
molinos harineros, ferrerías o molinos de papel, del aprovechamiento de la energía hidráulica en época medieval.

Abatanar el paño consistía en limpiarlo de las impurezas que había ido adquiriendo en los anteriores procesos de manufactura; entre las principales podemos destacar el aceite que se aplicaba a la lana para facilitar su cardado, la saliva con que se untaba durante la hilatura, la suciedad adquirida durante la fase de textura en el telar, adherencias de motas y polvo sufridas durante el transporte y manipulación del paño y, en último término, restos de la propia suarda o grasa natural contenida en el pelo de la oveja. Esta limpieza se lograba mediante la aplicación de un tratamiento consistente en revolver bien el paño con sustancias desengrasantes (en época bajomedieval las más empleadas, con diferencia, fueron la greda y el jabón) que, combinadas con agua caliente, eliminaban por completo las grasas y suciedad impregnadas en el tejido, mientras era golpeado rítmicamente por los pies del batanero (en el sistema manual) o por los grandes mazos de madera (en el mecánico). Pero el abatanado tenía como segunda finalidad la de enfurtir el tejido, es decir, proporcionarle un cuerpo más firme y una resistencia superior. Todos sabemos que cuando la lana está recién tejida, las fibras se hallan muy abiertas y esponjosas, abriéndose y deformándose con facilidad. Para evitar este problema, las sustancias desengrasantes mencionadas actuaban también como astringentes que conseguían apretar el entramado de la fibra, haciéndolo más tupido y resistente. Cuanto más espacio había entre los hilos, mayor enfurtido y un tratamiento más prolongado necesitaba el tejido para lograr la necesaria firmeza ${ }^{4}$.

El proceso del abatanado se iniciaba con la realización de algunas operaciones previas al golpeo del tejido. Cuando el paño llegaba a manos de los pelaires ${ }^{5}$ debía ser, primero, lavado en agua caliente y, acto seguido, despinzado. Despinzar consistía en limpiar el paño de hebras y nudos, cortar los hilos sobresalientes y perfilar, en general, cualquier imperfección que trajese del telar, lo que se hacía mediante el uso de tijeras y pinzas. Las Ordenanzas Generales de Paños de 1511 se refieren a esta operación cuando afirman que despinzar consistía en eliminar de los paños motas, cadillos $y$ pajas... de modo que queden bien limpios ${ }^{6}$. A continuación el paño era limpiado del aceite y grasa acumuladas durante la textura y anteriores procesos de elaboración mediante su introducción en una mezcla de agua caliente con greda o arcilla arenosa que las Ordenanzas de 1511 denominan melecina, insistiendo en cuidar su adecuada composición. La greda actuaba como astringente, al modo como lo hace el talco sobre las manchas de aceite, y se eliminaba con facilidad en los posteriores baños de agua. La operación era llamada desuardar, en el sentido de librar al paño de la suarda o grasa de la lana ${ }^{7}$. La tierra de batanar más utilizada en la Corona de Castilla durante el período bajomedieval fue la procedente de una variedad de greda extraída en la localidad toledana de Magán, cuya proximidad geográfica al valle del Guadalquivir

\footnotetext{
${ }^{4}$ R. Córdoba, Las técnicas, pp. 347-348.

5 Pelaire es el término derivado del catalán paraire, y éste a su vez del latín parator que, con el significado de «preparador», fue utilizado en Castilla para designar a los oficiales encargados del abatanado del paño y de los procesos auxiliares al mismo. En la Corona de Aragón el pelaire fue, más que un trabajador manual, un organizador-director del proceso de trabajo en esta fase de la confección del paño (véanse sobre este particular las reflexiones de M. Bernat, Els "III Mesters de la Llana”, pp. 82 y ss.; P. Iradiel et al., Oficios, pp. 95 y ss. y también p. 155; J. Bordes, Desarrollo, pp. 169 y ss.); pero en la de Castilla, al menos en sus territorios meridionales, el término se aplicó al trabajador manual que arrendaba el batán, llevaba a cabo directamente las distintas operaciones relacionadas con esta labor (personalmente o contratando para ello personal asalariado) y se ocupaba de la realización de todo el proceso, desde el despinzado al cardado a la percha.

${ }^{6}$ Ordenanzas Generales de Paños de 1511, AMCO, Sección VI, Serie 7, Legajo 18, cap. 54 ${ }^{\circ}$.

${ }^{7}$ P. Iradiel, Evolución, pp. 198-201; R. Córdoba, La industria, p. 58.
} 
contribuye a explicar que prácticamente no se documente el uso de otra variedad. Ibn Hawqal, al citar dicha localidad en el siglo X, ya se refiere a ella como el lugar de donde se extrae la tierra de batanar española, y disponemos de numerosos testimonios sobre su uso en la Baja Edad Media y en siglos posteriores ${ }^{8}$.

Una vez aplicados los citados tratamientos de limpieza, el paño era introducido en la pila del batán donde, mediante golpes de mazo, tenía lugar la fase de abatanado propiamente dicho, operación que tenía como finalidad la de enfurtir el paño. Enfurtir significaba dotar al paño de consistencia y resistencia, apretando la fibra para que no se abriera con el uso del tejido. Se lograba haciendo girar el paño en el interior de la pila, rodándolo y torciéndolo repetidas veces mientras estaba empapado en agua con greda y jabón. El tratamiento provocaba la reducción de su peso y longitud: en Córdoba, y según recogen ordenanzas municipales del siglo XV, los paños de 30 varas en jerga debían salir del batán midiendo 27 varas, lo que suponía reconocer una pérdida del $10 \%$ de su longitud ${ }^{9}$. Esta fase de la operación era muy delicada, pues los mazos podían dañar el tejido si lo golpeaban con una fuerza excesiva, durante un período de tiempo demasiado prolongado o repetidamente sobre la misma superficie, de forma que los bataneros debían estar muy atentos para ir volviendo el paño durante el proceso y mantenerlo siempre en disposición para ser golpeado de manera eficaz. Entre los desperfectos más habituales que los paños podían sufrir en esta operación se suelen citar el salir vacíos de codena (es decir, sin la necesaria resistencia en las fibras), picados, rajados (por efecto de los golpes) o mal desuardados (si todavía contenían grasa $)^{10}$.

Terminado el tratamiento, los paños eran puestos a secar antes de pasar a la última fase del proceso. En Barcelona este secado se hacía en un lugar abierto llamado el Camps dels tiradors, propiedad de la cofradía de pelaires, severamente custodiado por un guarda dels tiradors que impedía el acceso a toda persona ajena al oficio y velaba por el buen estado de los paños allí extendidos ${ }^{11}$. Las Ordenanzas Generales de 1511 prohíben el uso de tiradores provistos de barras o puntas que permitan ensanchar o estirar el paño para hacerle adquirir mayores dimensiones después del abatanado ${ }^{12}$. Y las municipales de la localidad albacetense de Chinchilla disponían que los pelaires que tirando los dichos paños o retales, dejaren de enclavar bien las susodichas piezas, que por cada clavo que falleciere o estuviere de menos en el tirador, caigan en pena de $1 \mathrm{mr}^{13}$.

Concluido el proceso de abatanado propiamente dicho, los propios pelaires eran los encargados de efectuar sobre los paños el denominado cardado a la percha,

\footnotetext{
${ }^{8}$ Sobre el uso de la greda de Magán en época moderna y contemporánea, L.A. Braojos, Explotación y comercio, vol. VI, pp. 119-126; F. Reyes, J.I. Gil, M.L. Menéndez, Organización, pp. 191-203. La cita de Ibn Hawqal en R. Córdoba, Influencia, p. 597. Aunque no en todos los lugares y épocas se utilizó la greda de Magán, sobre todo en comarcas alejadas geográficamente de Toledo que hubieron de recurrir a materias locales; Severino Pallaruelo afirma que en el Altoaragón y en períodos históricos más recientes, se utilizó la llamada «tierra blanca de Figueruela», greda que usaban los bataneros de Barbastro y que procedía probablemente de una gran finca comunal llamada Figueruela, sita en término de la ciudad, junto al río Cinca (S. Pallaruelo, Los molinos, p. 215).

${ }^{9}$ R. Córdoba, La industria, pp. 58-59. Munro afirma que los paños perdían durante el abatanado hasta un $30 \%$ de la longitud inicial y un $35 \%$ del peso con el que salían del telar, pero dichas proporciones parecen excesivas para lo que se documenta en el caso cordobés (J.H. Munro, Textile Technology, p. 19).

${ }^{10}$ R. Córdoba, La industria, p. 59; M. Martínez, La industria, p. 59.

${ }^{11}$ P. Bonnassie, La organización, p. 153.

12 Ordenanzas Generales de Paños de 1511, AMCO, Secc. VI, Ser. 7, Leg. 18, cap. $62^{\circ}$.

${ }_{13}$ A. Bejarano, A.L. Molina, Las ordenanzas, p. 144.
} 
tal y como aparece documentado en contratos de aprendizaje como el firmado en 1470 entre el pelaire cordobés Diego Torrijos y un tal Antón, por el que el primero se comprometía a enseñar el oficio al aprendiz, incluido el cardar a la percha ${ }^{14}$. La operación consistía en colgar los paños de tiradores o ramblas (de donde procede el término enramblar que era utilizado para designar la colocación del paño en el tirador), bastidores de madera en los que se sujetaba el paño mediante escarpias colocadas a lo largo de barras paralelas ajustadas al ancho de la tela. Una vez colgados, se cardaban pasando repetidas veces sobre ellos un modelo especial de carda llamado palmar, consistente en un armazón alargado de madera sobre el que se sujetaban numerosas cabezas de cardón o cardencha. Su uso procedía de antiguo, puesto que ya se documenta la existencia de palmares integrados por espinas de cardencha en la Hispania romana, donde fueron conocidos por el nombre de aena fullonia ${ }^{15}$.
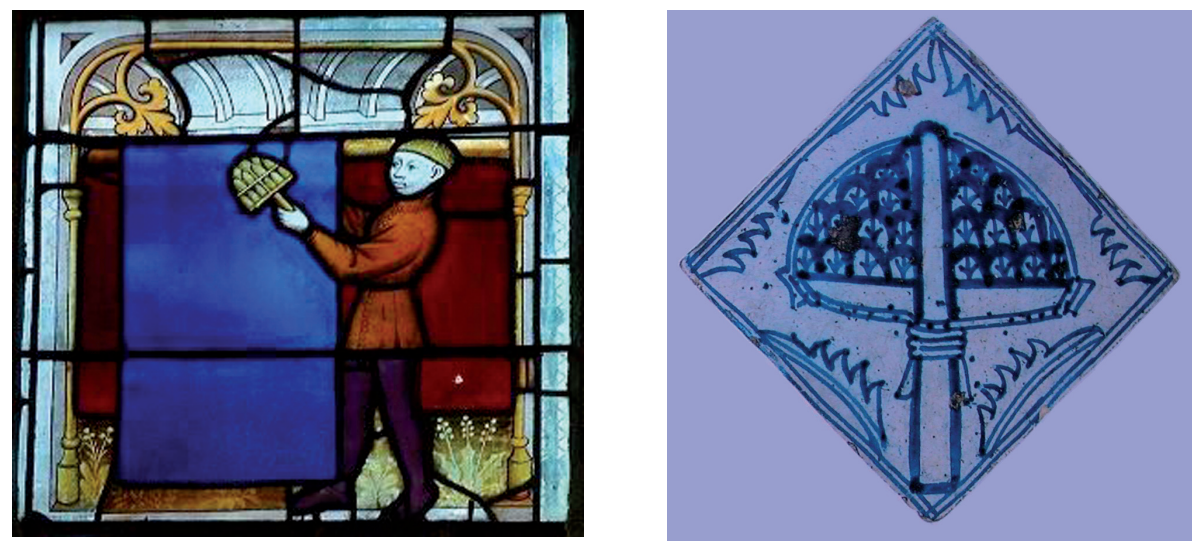

Fig. 1. Cardado a la percha de los paños, representado en una vidriera de la llamada iglesia de los pañeros, en la localidad francesa de Semur-en-Auxois (fotografía Daniel Villafruela); y azulejo de Manises del siglo XV que representa un palmar cuajado de cabezas de cardón listo para el trabajo (fotografía B. Martínez).

El cardón o cardencha es un término que se aplica a diversas plantas espinosas caracterizadas por disponer de cabezas de espinas, aunque según Margalida Bernat la variedad más utilizada en época medieval fue el Dipsacus fullonum ${ }^{16}$. El cultivo del cardón conoció un destacado auge a fines de la Edad Media, cuando se pusieron en marcha numerosas plantaciones de la que se convirtió en una imprescindible planta de

${ }^{14}$ R. Córdoba, La industria, p. 60.

${ }^{15}$ C. Alfaro, Tejido, p. 227. Por supuesto, en época medieval se hallaba completamente prohibido el uso de cardas con púas o alambres de hierro en esta operación; numerosas ordenanzas locales repiten estas disposiciones, en tanto las Generales de Paños de 1511 multan con 600 mrs. por la primera vez, pena doblada por la segunda y $3000 \mathrm{mrs}$. y privación del oficio por la tercera, al pelaire que las utilizara (AMCO, Secc. VI, Ser. 7, Leg. 18, cap. 60).

${ }^{16}$ M. Bernat, Els "III Mesters de la Llana”, p. 57. También lo fue en el mundo romano (A. Uscatescu, Fvllonicae et Tinctoriae, pp. 36-37). Pero es probable que se usaran otras variedades, puesto que la planta conocida en catalán como "cardó de paraire" corresponde a la especie Dipsacus sativa. 
uso industrial, como el zumaque, el lino y tantas otras. En la provincia de Córdoba, se documenta su cultivo en amplias zonas de la Campiña, como Montilla y Guadalcázar, y en las huertas existentes en los alrededores de la propia ciudad de Córdoba, lugares de donde solía proceder el cardón empleado por los bataneros de la capital; las cabezas de cardón se vendían por millares, oscilando su precio entre los 20 y los 60 mrs., y solía ser recogido durante el mes de julio, pues todos los contratos acuerdan su entrega en un plazo comprendido entre los 20 y los 30 días pasado el de San Juan de junio ${ }^{17}$. Pero las explotaciones donde se sembraba y cosechaba cardón se hallaban extendidas en el siglo $\mathrm{XV}$ por todo el valle del Guadalquivir, pues encontramos contratos suscritos por pelaires que trabajaron en las localidades de Castro del Río (Córdoba), Jaén o Sevilla, y que lo emplearon para el cardado a la percha de paños y otras obras de lana, como los bonetes ${ }^{18}$.

El palmar se pasaba repetidas veces sobre ambos lados de la tela; aunque podía llevarse a cabo sobre el paño seco o mojado, Margalida Bernat afirma que solía emplearse la segunda modalidad (paño húmedo), mientras que las Ordenanzas Generales de 1511 recomiendan dar al paño una pasada de palmar (definida como "traite") preliminar en seco y, a continuación, una o dos más, ya sobre el paño bien mojado ${ }^{19}$. El mal estado de los cardones colocados en el palmar, la mala utilización de dicho instrumento, el estado excesivamente mojado del paño, eran factores que solían ocasionar defectos de producción en el paño cardado. Las ordenanzas de pelaires de la localidad albacetense de Chinchilla, de 1484, fijan una sanción de 2 mrs. para el pelaire que hiciera en el paño un agujero en que cupiere el dedo corazón, 5 mrs. si cupiere un huevo, $10 \mathrm{mrs}$. por el puño y $20 \mathrm{mrs}$. por el palmo; por su parte, las ordenanzas mallorquinas prohíben dar a los paños cardados cualquier apresto que disimulase los

${ }^{17}$ En 1471 Juan de Ruz, vecino de Montilla, vendía a dos pelaires cordobeses el cardón que tenía sembrado en un majuelo cercano a Montilla, acordando entregarlo hasta veinte días después de San Juan de junio, a precio cada millar de 60 mrs. (1471.08.26, AHPCO, PNCO, Leg. 14110P, Cuad. 4, f. 33v); y Alfonso López vendía a Perucho Vizcaíno, pelaire de Córdoba, «todo el cardón que tiene sembrado en dos hazas de tierra y dos majuelos y un pedazo de olivar que están cerca de la villa de Montilla» por 60 mrs. el millar (1471.09.09, AHPCO, PNCO Leg. 14110P, Cuad. 5, f. 47r); tres años más tarde otro vecino de Montilla vendía a un trapero cordobés 50 millares de cardón «tal como lo cogiere de su cosecha cogido en tiempo y sazón, hasta un mes después de San Juan Bautista», a 20 mrs. el millar (1474.03.01, AHPCO, PNCO, Leg. 13665P, Cuad. 5, f. 64r). En 1489 un hortelano de Guadalcázar vendía a un pelaire de Córdoba 20 millares de cardón «bueno de dar y de tomar que tiene sembrado en una huerta que posee en término del dicho pueblo», a precio cada millar de $21 \mathrm{mrs}$., acordando entregárselo la semana de San Juan Bautista (1489.02.20, AHPCO, PNCO, Leg. 14129P, Cuad. 4, f. 38r). En febrero de 1497 el hortelano Miguel Sánchez vendía al pelaire Alfonso Ruiz, 112 eras de cardón sembradas en la huerta de Santa María, cercana a la ciudad de Córdoba, a precio cada era de 23 mrs., acordando dárselo «bien labrado y criado», y en diciembre de 1498 Pedro Sánchez hacía lo propio al vender «cien eras de cardón plantado y criado en la huerta que dicen de Mexuare, allende la puente mayor de esta ciudad... criado a vista de hombres que de ello sepan» (1497.02.13, AHPCO, PNCO, Leg. 14135P, Cuad. 17, f. 54r y 1498.12.02, AHPCO, PNCO, Leg. 14137P, Cuad. 6, f. 27v).

${ }_{18}$ Así, el tundidor Rodrigo de Soria, vecino de la sevillana collación de Santa María, vendía en 1497 al bonetero Juan Bautista, «todo el cardón que hubiere menester para su oficio de bonetero, que hoy día tiene sembrado en la huerta que dicen del Bachiller», a precio cada millar de cinco reales (1497.05.19, AHPSE, PNSE, Leg. 3.2, f. 145v); en 1507 es Andrés Fernández, un pelaire vecino de Jaén, quien reconoce deber a Martín Alfonso $452 \mathrm{mrs}$. que le restan por pagar del importe de la compra de «ciertos millares de cardón» (1507.05.11, AHPJA, PNJA, Leg. 11, f. 366r); mientras que en 1530 Juan Martín, pelaire vecino de Castro del Río, se obligaba a pagar a Bartolomé Sánchez Sobrino, hortelano vecino de dicha localidad, $4.080 \mathrm{mrs}$. por precio de 40 haces de cardón que le compró a tres reales cada uno (1530.07.27, AHPCO, PNCS, Leg. 4962P, f. 67r).

${ }_{19}$ M. Bernat, Els “III Mesters de la Llana”, p. 189; Ordenanzas Generales de Paños de 1511, AMCO, Secc. VI, Ser. 7, Leg. 18, cap. 59 . 
defectos producidos durante dicho proceso, práctica que en la ciudad de Cuenca se documenta por el nombre de mendecinar el paño ${ }^{20}$.

\section{LOS BATANES HIDRÁULICOS}

\subsection{Origen y expansión del batán hidráulico}

El sistema técnico usado por los batanes está basado en la utilización de la rueda hidráulica vertical y del árbol de levas, siendo idéntico al empleado en ferrerías y molinos papeleros, de forma que cabe preguntarse a cuál de estos procesos sería aplicada primero la que parece ser una invención mecánica medieval (el árbol de levas), si al abatanado de los paños, martilleo del metal o triturado de trapos. Lo que parece innegable es que se trata de un sistema desarrollado a partir del mecanismo impulsor de las aceñas, basado igualmente en el empleo de la rueda hidráulica vertical conectada a una rueda dentada y linterna.

Todos los investigadores coinciden en señalar que el abatanado mecánico de los paños de lana comenzó a ser usado en Europa en el siglo X, puesto que a dicha centuria corresponden los testimonios documentales más antiguos que poseemos sobre su uso; aunque en estos casos siempre quepa la duda de si la invención fue anterior y lo que ocurre simplemente es que carecemos de noticias, tanto de carácter documental como arqueológico, anteriores al siglo X. En cualquier caso, lo cierto es que hasta la fecha las menciones más antiguas que poseemos sobre batanes hidráulicos se remontan a la segunda mitad de dicho siglo en el centro y norte de Italia, Abruzzo en el año 962, Parma en el 973, Verona en 985, Milán $1008^{21}$. En la Europa atlántica, las primeras menciones no llegan hasta un siglo más tarde: hallamos batanes hidráulicos citados en Argentan, localidad cercana a Rouen en Normandía, a finales del siglo XI (1086) ${ }^{22}$ y en Inglaterra a finales del XII (dos batanes, en Yorkshire y Cotswolds, datan de 1185) ${ }^{23}$; en Polonia, las primeras citas se remontan a los primeros años del siglo XIII (1212) ${ }^{24}$; y en Portugal las primeras referencias datan de mediados de dicho siglo, cuando se otorgan diversas licencias reales para su construcción, aunque su generalización se produciría durante el siglo XIV, como documenta Maria Helena Coelho en la cuenca del Monde$\mathrm{go}^{25}$. En Inglaterra la generalización de su uso habría tenido lugar igualmente durante el siglo XIV, para el que se conocen 120 o 130 batanes repartidos por todo el país; y aunque no han sido estudiadas muchas evidencias arqueológicas, es conocido en ese ámbito geográfico el batán que funcionó en Fountains Abbey y algunos otros establecidos a fines de la Edad Media en Old Ford, Straford, Wandsworth, Enfield y Stepney ${ }^{26}$.

Parece que los inicios de su uso en la España cristiana son coetáneos, incluso anteriores, a las más antiguas menciones documentales halladas en otros territorios europeos, puesto que se remontan a principios del siglo X. En 918 se data la donación realizada por Ordoño II al obispo Frunimio en la que se habla de per carrera que com-

${ }^{20}$ J.D. González, La industria, p. 39; M. Bernat, Els “III Mesters de la Llana”, p. 189; P. Iradiel, Evolución, p. 204.

${ }^{21}$ P. Malanima, The first, pp. 117-118; J.H. Munro, Industrial, p. 245; L. White, Tecnología, p. 100

${ }^{22}$ A.M. Bautier, Les plus, p. 571; J. Gimpel, La revolución, p. 72.

${ }^{23}$ E. Carus-Wilson, An Industrial, pp. 39-60; R.V. Lennard, An Early, p. 150; R. V. Lennard, Early English, pp. 342-343.

${ }^{24}$ M. Daumas, Les origines, p. 467.

${ }_{25}$ A. de Carvalho, Engenhos, p. 30; E. Veiga, F. Galhano, Tecnologia.

${ }^{26}$ H. Clarke, The Archaeology, p. 134; E. Crowfoot, F. Pritchard, K. Staniland, Textiles, p. 17. 
porta ad illos pisones ${ }^{27}$. Para el siglo XII contamos con diversas referencias al uso de batanes en ámbitos tanto de la Corona de Castilla como de Aragón. En el vallisoletano Valle de Trigueros se citan en 1153 quinque acenias et unum molendinum ropero; distintos molins drapers son citados en localidades catalanas por esas mismas fechas, como Prat de Mollo (1151), Salt (1166) y Lleida (1191); en enero de 1183 Esteban, obispo de Huesca, donó unos molinos junto al río Vero a Jimeno de Doña Guinta y su esposa Sancha, entre los que se incluía un molendino trapero que ibi fecit Guillem de Carcassona; en 1193 los templarios de Huesca compraron de Garión de Abós un molin draper situado junto al río Aragón, cerca de Jaca; y en 1190 Juan Utrilla documenta la formación de una compañía de empresarios para la construcción de un batán en la localidad de Tierz, cerca de Huesca ${ }^{28}$. En el siglo XIII ya debían ser frecuentes en Castilla pues Las Partidas de Alfonso X hablan de aceñas para pisar paños y disponemos de menciones en distintas comarcas de Salamanca y Palencia desde 1210; en la Corona de Aragón se mencionan molinos traperos en Bagá (1257) y Lleida (1280) y aparecen igualmente referenciados en el coetáneo Fuero de Teruel ${ }^{29}$. Para finales de dicho siglo, José Ignacio Padilla ha podido estudiar el coste de construcción de un batán en Lleida gracias a la conservación de sus cuentas ${ }^{30}$.

Por tanto, parece claro que los batanes hidráulicos se difundieron por la Península Ibérica en el curso de los siglos XI-XII, momento en que en al-Andalus se estaba empleando también una tecnología hidráulica muy desarrollada, incluyendo el uso de norias fluviales, aceñas harineras e ingenios hidráulicos basados en el árbol de levas como los molinos papeleros de Xátiva ¿Por qué, entonces, no ha sido posible documentar el uso de ningún batán en al-Andalus? Parece sorprendente que una tecnología bien conocida no fuera empleada para esta finalidad concreta, pero hasta la fecha, hay que insistir, no ha sido documentado el uso de batanes hidráulicos en la España musulmana ${ }^{31}$. Esta falta de documentación lleva a afirmar a Margalida Bernat que los andalusíes no llegaron a utilizar este tipo de ingenio en la Mallorca del siglo XIII, siendo introducido por los cristianos ${ }^{32}$. Y lo mismo hubo de ocurrir en el sur de la Península, según parece deducirse de la documentación conservada, que es muy tardía; no aparecen citados en documentos de la época de la conquista, donde se repartieron numerosas instalaciones industriales, aceñas y tintorerías, entre otras, y nunca se mencionan batanes ni por dicho nombre ni por un término homónimo (pisón, molino trapero) que pudiera hacer referencia a batanes hidráulicos. Ello permite suponer que el uso del batán hidráulico sería introducido en las localidades de la cuenca del Guadalquivir durante el siglo XIV, pues parece que ya era usualmente empleado en la primera mitad del siglo XV. Lo mismo parece suceder en la zona de Albacete, donde en el siglo XIV se menciona ya la existencia de batanes mecánicos en Chinchilla, Almansa y quizás Alcaraz, sobre el río Júcar y la acequia de Alpera ${ }^{33}$.

El problema fundamental es la falta de documentación que existe para ese período, de forma que es difícil datar con precisión los años en que pudo ser introduci-

${ }^{27}$ E. Sáez, Colección, vol. I, pp. 73-74. Aunque cabe preguntarse si se refiere a batanes hidráulicos, o incluso a batanes de paños.

${ }^{28}$ E. García, La terminología, p. 71; M. Gual, Orígenes, p. 514; S. Pallaruelo, Los molinos, p. 208; J.F. Utrilla, Los orígenes, pp. 809-810.

${ }^{29}$ E. García, La terminología, p. 71, notas 13 y 14; N. García, Técnica, p. 102; J. Caro Baroja, Sobre maquinarias, pp. 479-481; I. González, Fábricas, p. 395; J.F. Utrilla, Los orígenes, p. 807.

30 J.I. Padilla, La construcció, pp. 105-128.

${ }^{31}$ R. Córdoba, Some Reflections, p. 941.

${ }_{32}$ M. Bernat, Los batanes, p. 407.

${ }_{33}$ J. Sánchez, Noticias documentales, pp. 34-35. 
do. Las menciones solo se hacen habituales a partir de mediados del siglo XV, cuando contamos con contratos de arrendamiento. En el río Guadalquivir la primera mención de un batán hidráulico es la realizada en octubre de 1440 cuando María Alfonso, viuda de Alfonso Fernández de Argote, traspasó a su hija Beatriz Fernández, monja del Monasterio de Santa María de las Dueñas, y a la abadesa y profesas internadas en el mismo, tres octavas y media partes de las aceñas, batán y pesquería de Fernando Alonso, en el río Guadalquivir término de Montoro. En 1463 Alfonso López, pelaire vecino de Córdoba en la collación de San Andrés, arrienda al también pelaire Martín Sánchez de Úbeda, la cuarta parte del Batán Luengo en la parada de San Julián, por un año y renta de 875 mrs. Y en 1468 el citado pelaire Martín Sánchez de Úbeda, vecino en la parroquia de San Pedro, subarrendaba al pelaire Pedro Ruiz, la tercera parte del batán que tenía arrendado de Alfonso de Aguilar, como mayordomo de Fadrique Manrique, cerca del Puente de Alcolea, por tiempo de un año y renta anual de mil mrs. ${ }^{34}$.

Desde el punto de vista cronológico son paralelas las primeras menciones que de este tipo de instalaciones tenemos en el río Guadajoz, pues se remontan a los años 1461 y 1464. En octubre de 1461 Diego Fernández de Córdoba, mariscal de Castilla, dona a su hijo Martín de Córdoba los batanes de Iscar, cuyo rendimiento anual se estimaba en esa fecha en 24.000 mrs. Y en julio de 1464 Francisco Sánchez, pelaire vecino de Córdoba en la collación de Santa Marina, subarrendaba a otro pelaire, de nombre Juan Díaz, la tercera parte del denominado Batán Pequeño que él mismo tenía a renta de Nuño Mejía en la parada de batanes de Cucarrón, en el río Guadajoz, por tiempo de un año y renta anual de 1.200 mrs. ${ }^{35}$.

Quizás porque su introducción se había producido una centuria antes, quizás porque en ese momento se hallaba en plena expansión la actividad textil en las ciudades del valle del Guadalquivir, lo cierto es que todavía a fines del siglo XV se registra una gran actividad en la construcción de nuevos batanes, tanto por lo que se refiere a la concesión de licencias para su instalación por parte del concejo de Córdoba, como por lo que hace referencia a la transformación en batanes de instalaciones que habían sido hasta entonces molinos de harina (aceñas) o a la edificación de nuevos edificios. Por ejemplo, en noviembre de 1468 el aladrero Juan López, vecino de Córdoba en la parroquia de Santa Marina, recibía del trapero Juan Trujillo $2050 \mathrm{mrs}$. como parte de pago de un batán que le ha de hacer en la parada del Vado del Adalid por precio de 3450 mrs., indicándole el trapero el lugar donde pudiera asentar dicho batán; en febrero de 1484 Luis López, aladrero vecino en Santa Marina, acordaba hacer de nuevo para el pelaire Luis López el llamado Batán Grande del Puente de Alcolea, propiedad por mitades de la Iglesia Mayor y de Juan de Ayala, señor de Villalba y Cebolla; en febrero de 1493 era Pedro Fernández, vecino de San Pedro, quien arrendaba de Martín de Úbeda, pelaire de la misma vecindad, un batán que el primero otorgó darle hecho y acabado por el día de San Juan en la parada de Casillas, con una casa fuera en que use del oficio de pelaire, a condición de que el arrendatario pusiera a su costa los mazos del batán; por último, en enero de 1496 el concejo de Córdoba daba licencia a Bartolomé del Castillo para edificar en término de Montoro y sobre el río Guadalquivir un batán para adobar paños ${ }^{36}$.

34 1440.10.18, Tumbo del Monasterio de San Jerónimo, AHPCO, Secc. Clero, Legajo 6532, f. 62; 1463.09.02, AHPCO, PNCO, Leg. 14105P, f. 334r; 1468.05.06, AHPCO, PNCO, Leg. 14107P, Cuad. 10, f. 22r.

35 1461.10.31, AHN, Sección Nobleza, Fondo de Luque, Caja 796, doc. no 30 (documento que contiene otro de toma de posesión de los batanes con fecha 1461.11.01); 1464.07.02, AHPCO, PNCO, Leg. 14104P, Cuad. 10, f. 35v.

36 1468.11.14, AHPCO, PNCO, Leg. 14106P, Cuad. 2, f. 254v; 1484.02.25, AHPCO, PNCO, Leg. 14122P, Cuad.9, f. 39v; 1493.02.25, AHPCO, PNCO, Leg. 14131P, Cuad. 5, f. 11v; y 1496.01.22, AMCO, LAC $4^{\circ}$, Secc. 19, Ser. 2. 


\subsection{Ubicación y explotación de los batanes}

La edificación de todos estos inmuebles durante el siglo XV vino a completar la red de instalaciones que, para el abatanado de los paños de lana, existió en la cuenca del Guadalquivir a fines del siglo XV y principios del XVI. Los principales batanes que tenemos documentados durante esos años en el entorno de la ciudad de Córdoba son los siguientes: sobre el río Guadalquivir, conocemos un batán situado en las aceñas de Fernando Alonso, en término de Villaverde, Montoro; otro más en la parada de San Martín, ubicada igualmente aguas arriba de Montoro, que tenemos documentado desde mediados del siglo XVI; un batán en la parada de Pajares, término de Montoro, llamado el batán de la Acémila; y otro más en la parada de aceñas de Villafranca, en término de dicha población, entre El Carpio y Alcolea $^{37}$. En término de Córdoba, se localizan dos batanes, denominados Batanejo y Grande, en la parada situada junto al Puente de Alcolea, documentados desde la década de los años 60 del siglo XV; en la parada de San Julián, ubicada a la entrada del Guadalquivir en la ciudad de Córdoba, hubo al menos cuatro batanes -los dos llamados de Afuera, el Luengo y el Cortillo- que, tras la desaparición de la azuda en 1573 , fueron sustituidos por los seis batanes de nueva construcción establecidos en el molino de Martos entre los años 1565 y 1575; también en la propia capital, junto al puente mayor y en la parada homónima, un batán situado en las aceñas de Enmedio o del Infante -actual Molino de Pápalo o del Conde de Portillo- y otro edificado a fines de siglo en las aceñas de Don Tello ${ }^{38}$. En la parada de Casillas, unos $3 \mathrm{~km}$. aguas abajo de la ciudad, un batán propiedad del trapero Pedro Fernández edificado probablemente en 1493; y en la parada de Alhadra, cercana al Aguilarejo y Cortijo Rubio, la más alejada de la ciudad aguas abajo, tres importantes instalaciones conocidas por los nombres de batán de Santa María, del Agua Caliente y de Elvira Brava. Sobre el río Guadajoz, entre las poblaciones de Castro del Río y Baena, aunque en término municipal de la segunda, el batán de Iscar está documentado desde 1460; los dos batanes de la parada de Cucarrón, ya en término de Córdoba capital, lo están desde la misma fecha; y el batán de la parada de Parias, la más cercana a la desembocadura del río, desde $1482^{39}$.

37 1440.10.18, Tumbo del Monasterio de San Jerónimo, AHPCO, Sección Clero, Legajo 6532 , f. 59; venta de un tercio de dos piedras de pan en la parada de San Martín a Martín Ruiz Calaberuelo, con la inclusión de la sexta parte del batán, por 146.647 maravedíes (1553, AHPCO, PNMO, Leg. 7082P, s/f); en 1491 Juan de Angulo, comendador de Calatrava, arrienda a Martín Fernández, vecino de Montoro, el batán de la acémila en la parada de Pajares, término de dicha localidad (1491.07.29, AHPCO, PNCO, Leg. 14129P, Cuad. 6, f. 18r); en el libro de visitas que realizaron los visitadores de la Orden a la encomienda de Villafranca en 1463 se dice, «Otrosí por cuanto vimos las aceñas y el batán de la dicha vuestra encomienda y miramos el azuda de ellas, que está en algunos lugares aportillada y que si no se adoba y repara vendrá muy mayor daño, por lo cual vos mandamos que del día de San Miguel primero que vendrá en un año la hagáis reparar y la deis acabada y hecha porque como dicho es mayor daño no venga» (1463.07.06, ADM, Sección Priego, Leg. 25, Libros de Visitas de la Encomienda de Villafranca del año 1463).

${ }^{38}$ Francisco de Torrijos arrienda a Lope González y Rodrigo Alfonso la mitad de un batán que está en la parada de aceñas de don Tello, el cual es nuevo, desde el día de San Juan de junio por tiempo de un año y renta de 6.300 mrs. (1499.09.13, AHPCO, PNCO, Leg. 13665P, Cuad. 21$, f. $1 \mathrm{v})$.

39 1461.10.31, AHN, Sección Nobleza, Fondo de Luque, Caja 796, doc. nº 30; R. Córdoba, Molinos y batanes, pp. 48-51. Véase también Cuadro 1. 


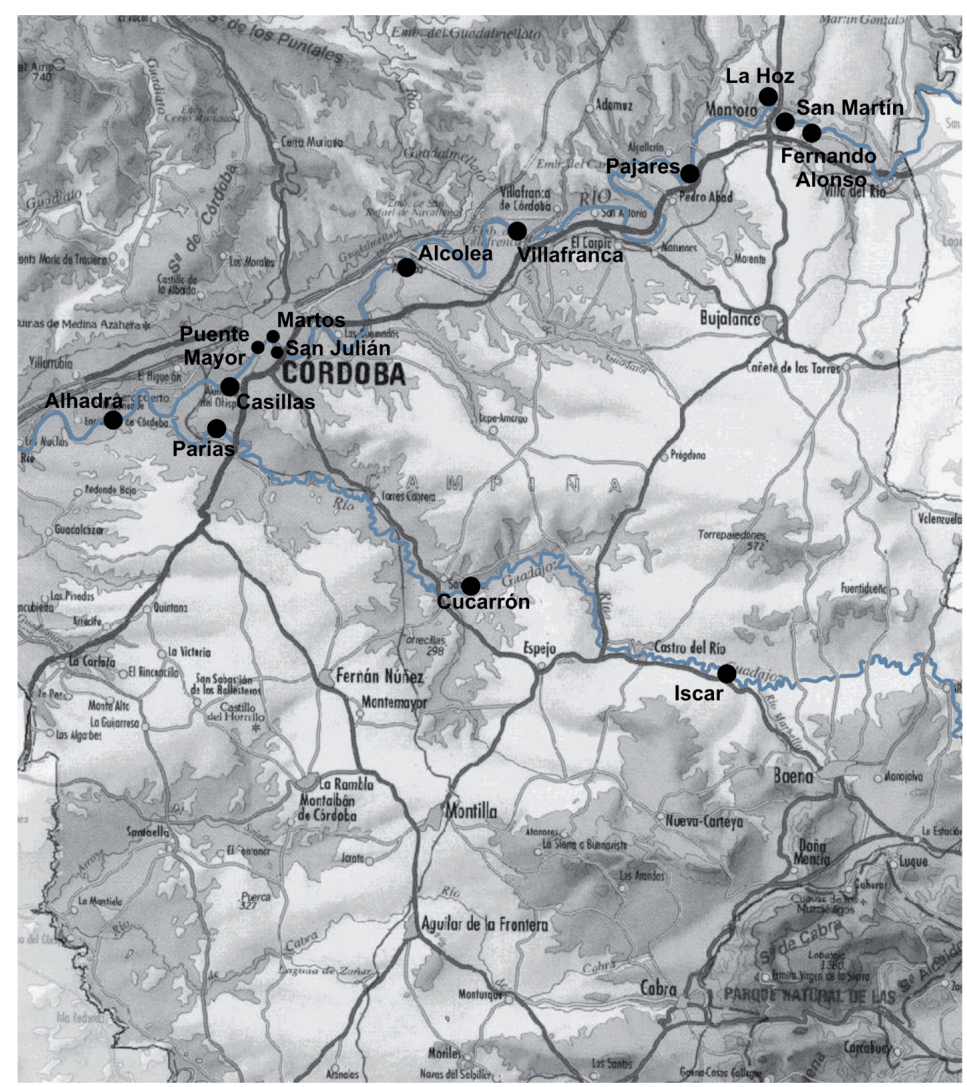

Mapa 1. Ubicación de los batanes mencionados en el presente estudio, en los ríos Guadalquivir y Guadajoz

(mapa 1:50000 del Servicio Cartográfico del Ejército).

Como podemos observar, en el caso de los ríos de la cuenca del Guadalquivir los batanes hidráulicos aparecen escalonados a lo largo de todo el recorrido, y no parece que estuvieran situados, de manera preferente, aguas abajo de las poblaciones junto a las que discurría el curso fluvial ni condicionados por el emplazamiento de los molinos harineros u otras instalaciones industriales. Refiriéndose al caso de Mallorca, Margalida Bernat afirma que las sustancias químicas usadas por los bataneros contaminaban de forma grave el agua utilizada en los batanes y que los propios batanes consumían abundante agua al necesitar mezclarla en las pilas con los paños, lo que los hizo incompatibles con el riego de cultivos huertanos; por este motivo, continúa, debían de haberse instalado siempre en la parte final del sistema hidráulico, pero en casos como Na Bastera se sabe que se instalaron al inicio, pervirtiendo todo el aprovechamiento del agua por debajo de ellos $^{40}$. Nada de eso se documenta en el caso que nos ocupa; hasta donde sabemos, los

\footnotetext{
${ }^{40}$ M. Bernat, Molins drapers, pp. 127-150; eadem, Aeris salubritate, pp. 253-286.
} 
batanes emplazados a lo largo del río Guadalquivir alternaron su emplazamiento con el de aceñas harineras y convivieron con ellas en el uso del agua desde la Edad Media hasta el siglo XIX, sin que aparentemente se registraran litigios con dichas instalaciones ni por consumo ni por contaminación del agua. Es más, en el caso del río Guadajoz, molinos y batanes compartieron emplazamiento con las norias fluviales destinadas a elevar el agua de riego con destino a las huertas situadas en sus márgenes, no resultando extraño que instalaciones industriales y agrícolas se ubicaran en la misma azuda ${ }^{41}$.

¿Cómo eran estos batanes desde el punto de vista arquitectónico? Como los restantes que albergaron instalaciones hidráulicas durante los siglos bajomedievales y modernos, solían ser edificios de piedra, rematados en forma absidal por la parte que enfrentaba a la corriente para resistir mejor su empuje, y provistos de frente recto por la parte opuesta. El interior, por lo general de planta cuadrada o rectangular, solía ir cubierto por bóvedas de medio cañón diseñadas para facilitar el discurrir del agua por la parte superior del inmueble durante las crecidas. Debido al aprovechamiento común de presas y canales, y al uso de unos mismos recursos técnicos para la captación de la energía, aceñas y batanes fueron instalaciones fácilmente intercambiables, por lo que resultó muy frecuente la conversión de unas en otras manteniendo las mismas azudas, edificios y canales ${ }^{42}$.

Algunos batanes se situaron en zonas exteriores de la instalación y aparecen ubicados al aire libre, en un lateral del complejo molinero. Así se refleja en el dibujo del siglo XVIII que, perteneciente a las aceñas y batanes de Fernando Alonso, se conserva en el Archivo de la Real Chancillería de Granada y que fue realizado con motivo de los pleitos por su jurisdicción que el concejo montoreño y los marqueses de la Vega Armijo mantuvieron durante esos años; en él aparece el batán ubicado en la orilla del río, junto al acceso a los dos edificios donde se hallaban las piedras de moler, y contiene una descripción que indica que las aceñas:

se componen de dos cuerpos cubiertos con tres bóvedas; que la una azeña a la entrada haze una embobedada que es paso para ellos y tiene nueve varas de largo y dos y media de ancho, y un cóncavo circular en el testero de seis varas de largo y tres de ancho; y la que tiene quatro piedras con ocho varas en cuadro; y de ésta al pasar a la que tiene una piedra ay una alcantarilla; y saliendo de dichas azeñas, los dos batanes al descubierto ${ }^{43}$.

Pero la mayor parte de ellos estuvieron albergados en edificios cerrados, siempre situados junto a los canales donde iban emplazadas las correspondientes ruedas verticales. En ese sentido, la fisonomía de muchos de ellos debió de resultar similar a la que actualmente presentan algunos batanes tradicionales conservados en la Península, como los de Mosquetín, en el concejo de Vimianzo (A Coruña), que comparten un único edificio abovedado, con suelo de piedra cruzado por canales donde se ubicaban las ruedas hidráulicas y las maquinarias de los batanes situadas entre ellos.

${ }^{41}$ R. Córdoba, J. Varela, El Patrimonio, pp. 34-46 y 241-250.

42 R. Córdoba, Los molinos, pp. 91-104. Por lo que se refiere a la transformación de antiguas aceñas en batanes, contamos con numerosos ejemplos datados a fines del siglo XV y primeros años del XVI, en relación con el desarrollo de la industria textil local; así, en 1493, el trapero Pedro Fernández, vecino de la collación de San Pedro, encargó al albañil Andrés Fernández, la realización de las obras necesarias en las aceñas de Casillas para convertir dos de las antiguas piedras de moler en dos batanes; en el contrato se especifican las reformas que se han de llevar a cabo para que puedan instalarse dos ruedas hidráulicas en el canal de la antigua aceña y los espacios necesarios para la maquinaria (1493.07.31, AHPCO, PNCO, Leg. 13669P, f. 123v).

43 1737, ARChGr, Caja 739, Pieza 2. Plano de la Dehesa de Villaverde, término de Montoro, y de las aceñas y batanes en el río Guadalquivir. 1 plano m.s. de tinta y aguada. Col. Papel, M., 58 x $70 \mathrm{~cm}$. 

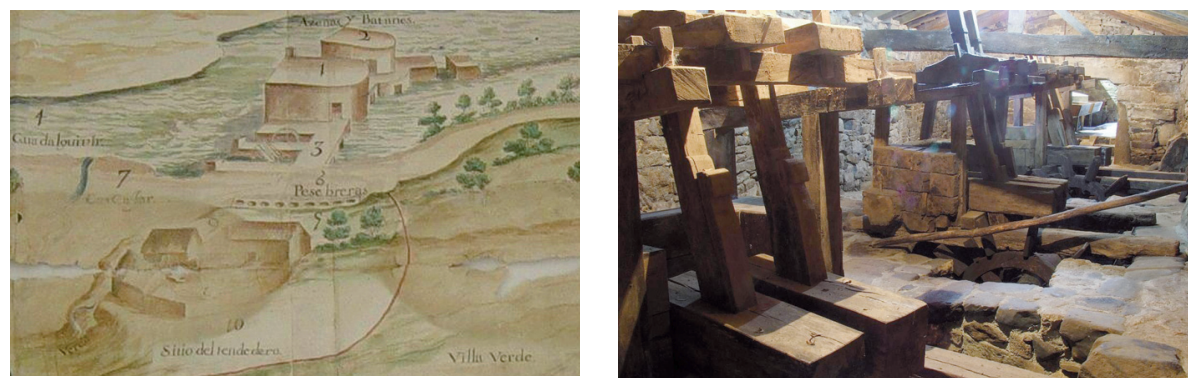

Fig. 2. Dibujo de las aceñas de Fernando Alonso en 1737; en primer término, con el número 3 , aparecen reflejados los mazos y rueda hidráulica del batán y, al fondo con los número 1 y 2, los dos cuerpos del molino harinero (Archivo de la Real Chancillería de Granada). A la derecha, vista interior de los batanes de Mosquetín, en A Coruña, ilustrativo ejemplo de configuración espacial de un batán medieval (fot. Javier Pais).

En el caso del Guadalquivir, el modelo de instalación que se encuentra mejor documentado es el de una aceña harinera, integrada por un solo edificio de planta rectangular, a uno de cuyos costados se adosa un espacio de dimensiones inferiores que alberga el canal y la maquinaria del batán, o que se encuentra separado del cuerpo principal de las aceñas por dicho canal. Así sucede, por ejemplo, en las aceñas del Infante o molino de Pápalo de la parada del Puente de Córdoba, cuya crujía principal acogió dos piedras de moler, mientras que el batán se situaba en el costado norte, en un espacio de $10 \mathrm{~m}$. de longitud por $4 \mathrm{~m}$. de anchura, que compartían el canal donde estaba emplazada la rueda (al norte) y una superficie de unos $3 \mathrm{~m}$. de anchura donde estaba instalada la maquinaria del batán (al sur); de la misma forma, en el molino de la Alegría el batán se disponía en un pequeño edificio propio, ubicado al norte del molino y separado de aquél por el canal de la rueda, y cuando en 1573 se construyeron los batanes del molino de Martos, se edificó ex-novo para albergarlos una nave especial situada en el lateral sur del gran edificio, de planta rectangular, donde iban las piedras de moler $^{44}$.

Unas instalaciones que, como acabamos de exponer, se difundieron ampliamente durante aquellos siglos a fin de obtener una clara mejora en la rapidez y rentabilidad económica del proceso de abatanado de los paños. Es cierto que la difusión del batán hidráulico no supuso la extinción del sistema de trabajo tradicional o, lo que es lo mismo, el abatanado de los paños a pie convivió con el uso de los batanes mecánicos en toda la Europa medieval; como han demostrado diversos investigadores, aún existen menciones de abatanar paños a pie en el Londres del siglo XIII, en la ciudad de Ypres durante el XVI y la famosa vidriera del batanero de la iglesia de Semuren-Auxois está datada en torno a los años 1470-1480; igual ocurre en la Península Ibérica, donde el Fuero de Cuenca, datado en los años 1190-1191, alude al abatanado manual de los paños, mientras el coetáneo de Teruel contiene ya menciones a molinos traperos $^{45}$. Este mantenimiento del procedimiento tradicional quizás tuviera mucho

${ }^{44}$ R. Córdoba, J. Cuenca, P. Hernández, J. Ortiz, Los molinos hidráulicos, pp. 157-160 y 203-204 del CD. El batán del molino de la Alegría fue objeto de una excavación arqueológica realizada en 1999 durante el proceso de restauración del edificio (R. Córdoba, Intervención, vol. I, pp. 361-369).

${ }^{45}$ R. Córdoba, Innovación, p. 344. 

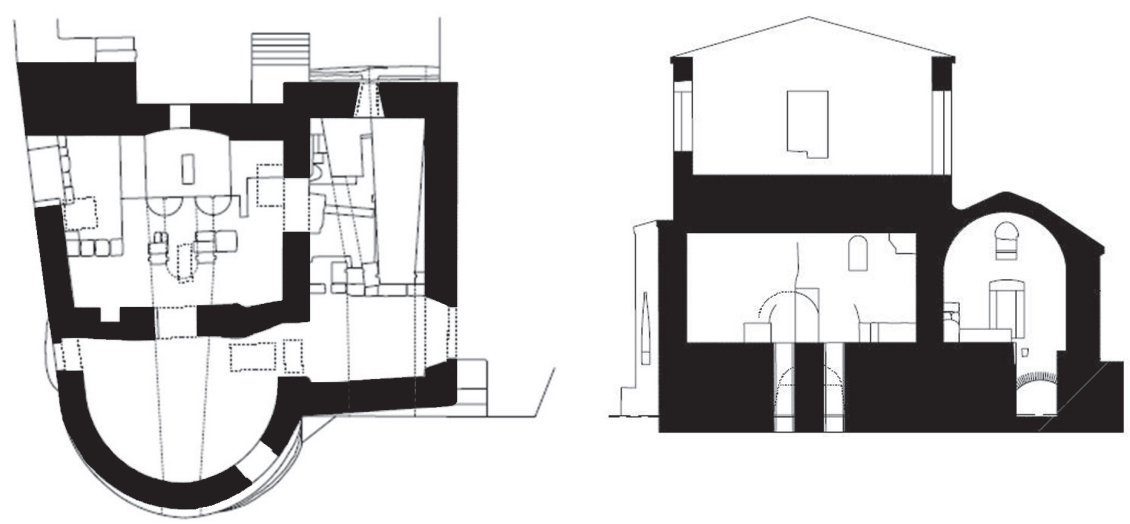

Fig. 3. Planos de planta y alzado del molino de Pápalo, ubicado junto al puente mayor de Córdoba, donde se observa la crujía principal, a la izquierda, dotada de dos piedras de moler, y la pequeña destinada a albergar la rueda y maquinaria del batán, a la derecha (planos: Juan Cuenca).

que ver con la necesidad de abatanar retales de paños y obras textiles de pequeño tamaño, para las que no compensaría, en términos económicos y de tiempo, el empleo del batán hidráulico, como pudo ocurrir con el abatanado que los boneteros hacían de los gorros de lana una vez tejidos a la aguja; por ejemplo, en julio de 1503 el bonetero cordobés Jaime de Morales, acordaba pagar en concepto de alcabala por la pierna de los boneteros, $3 \mathrm{mrs}$. por cada bonete doblado, 3 blancas por cada bonete sencillo y 4 mrs. por cada galota que batanare, lo que evidencia el tratamiento de ropas de reducido tamaño y peso ${ }^{46}$.

Pero no es menos cierto que la mejora en la rentabilidad que supuso el uso del batán hidráulico fue determinante para el desarrollo de la industria textil, hasta el punto de poderse hablar, como en su día hiciera Eleanor Carus-Wilson, de una revolución industrial del siglo XIII. Walter Endrei se planteó hace años la valoración, en términos numéricos, del aumento de productividad que habría supuesto el uso del batán hidráulico frente al tradicional sistema manual; según este autor, un proceso que anteriormente se prolongaba durante mil horas pasó a ser realizado en apenas cincuenta, reduciéndose a la 1/20 parte el tiempo de trabajo. Y aunque dichas cifras parecen algo exageradas, a la luz de las investigaciones más recientes John Munro ha podido afirmar que el uso del batán hidráulico redujo hasta en un $20 \%$ el coste de fabricación de un paño y hasta en un $70 \%$ el tiempo empleado en su abatanado ${ }^{47}$.

Además, la aplicación de la energía hidráulica al proceso y la consiguiente mejora en su productividad, trajo consigo importantes repercusiones de índole social al motivar el cambio de instalaciones a los grandes ríos y la concentración de la industria de acabado de paños en ciertas localidades, como se prueba en la Córdoba del siglo XV respecto a paños tejidos en Los Pedroches y otras comarcas de la pro-

46 1503.07.04, AHPCO, PNCO, Leg. 14142P, Cuad. 7, f. 35r.

${ }^{47}$ W. Endrei, Changements, p. 630; J.H. Munro, Industrial Energy, p. 254. 
vincia que recibieron en la capital la última fase de su tratamiento. Los testimonios que poseemos sobre la aplicación en Córdoba de esta fase del tratamiento a paños de lana tejidos en Los Pedroches son abundantes: en 1484 un vecino de Torremilano entregaba a batanar al pelaire Luis López, vecino de Córdoba, toda la ropa que trajere de aquí a Navidad; en 1494 el pelaire Diego Morillo juraba que el mes anterior Juan de Jaén le había dado a batanar un paño 22no blanco de Villapedroche; y en 1495 un trapero vecino de Chillón haber traído tres paños en jerga a Córdoba para adobarlos ${ }^{48}$. Así ocurrió también en el caso de algunos batanes del río Guadajoz, al convertirse en instalaciones que recogieron la producción pañera de las localidades de la Campiña cordobesa, como se acredita por el contrato que Pedro Sánchez, un pelaire vecino de Castro del Río, firmó en 1504 con Juan Miguel, vecino de Montemayor, para traspasarle la mitad del batán que tenía arrendado en el término de Castro para adobar la ropa que viniere de las villas de Montemayor, La Rambla y Fernán Núñez $z^{4}$.

Como es lógico, el aumento de la productividad de los batanes hidráulicos, unido al crecimiento exponencial de una industria textil que generaba cada vez mayores rentas, determinó que las grandes fortunas de la época pusieran sus ojos en el dominio de estas instalaciones a fin de asegurarse las jugosas rentas económicas que producían y el control social que proporcionaban, al depender de ellas la producción de pañería de cada lugar. Por ejemplo, el batán de Villafranca, que aparece referenciado en los diferentes libros de visita de la Orden desde fines del siglo XV, proporcionaba a la encomienda de Calatrava una sustanciosa renta que en 1459 ascendió a 3.000 mrs., se elevó en 1490 hasta los 14.000 mrs., volvió a descender ligeramente durante los años siguientes y alcanzó su máxima rentabilidad en 1501 con 14.500 mrs. La rentabilidad del batán se situaba únicamente por debajo de la del horno de pan que la encomienda poseía en la villa, que llegó a rentar 40.000 mrs. anuales entre los años 1490 y $1495^{50}$. Los batanes de Iscar rentaron en 146124.000 mrs. y las cifras alcanzadas por otros arrendamientos se pueden apreciar en el Cuadro 1.

Por eso, desde el momento mismo de su difusión, la propiedad de numerosos batanes del Guadalquivir estuvo en manos de la Nobleza, la oligarquía o las instituciones eclesiásticas que, además de beneficiarse de sus rentas, eran los únicos que podían hacer frente a los elevados gastos de compra y de mantenimiento que dichas instalaciones representaban. El regidor Fernando de Cárcamo poseía el de Santa María, en la parada de la Alhadra; el jurado Alfonso de Mesa, el de Elvira Brava en la misma azuda; y Diego Fernández de Córdoba, alcaide de los Donceles y señor de Chillón y Lucena, el llamado del Agua Caliente; Nuño Mejía y, tras él, su viuda Constanza Merlo y el hijo de ambos, Tristán de Merlo, fueron los propietarios de los batanes ubicados en la llamada parada de Cucarrón, sobre el río Guadajoz y en término de la propia capital; en tanto que Fadrique Manrique lo fue de uno de los situados junto al Puente de Alcolea y Juan de Ayala, señor de Cebolla, de la mitad del otro. La Iglesia Mayor fue copropietaria del batán Grande con Juan de Ayala y de cuatro más en la parada de San Julián, los dos de Afuera, el Luengo y el Cortillo, cuyos arrendamientos aparecen ininterrumpidamente testimoniados desde 1463 hasta principios del siglo $\mathrm{XVI}^{51}$. Cuando la propiedad de los batanes cambió de manos fue usual llevar a

48 1484.05.31, AHPCO, PNCO, Leg. 14122P, Cuad. 9, f. 135r; 1490.10.11, AHPCO, PNCO, Leg. 13668P, f. 1014r; 1495.01.06, AHPCO, PNCO, Leg. 14132P, Cuad. 13, f. 89v.

49 1504.12.28, AHPCO, PNCS, Leg. 4954P, f. 22v. Cit. R. Córdoba, La actividad, p. 194

${ }^{50}$ C. Quintanilla, Villafranca, pp. 291-292.

${ }^{51}$ R. Córdoba, Molinos y batanes, p. 55; ídem, Aceñas y batanes, pp. 113-126. El interés de la oligarquía cordobesa por las instalaciones industriales ha sido destacado por M. Cabrera, Oligarquía y negocio, p. 119, destacando la propiedad sobre los batanes situados en la Alhadra, Casillas, Alcolea 
cabo la habitual ceremonia de toma de posesión en el interior de la propia instalación. En 1475 Juan Muñoz, mayordomo del convento de Santa Inés de Córdoba, tomaba posesión de un batán en la parada de San Julián, y entrando en él echó mano de los maderos y mazos del dicho batán, cerró y abrió puertas de la casa en símbolo de posesión; y el 20 de julio de 1497 era Pedro de Góngora, en nombre de Gómez de Aguayo, quien tomaba posesión de la mitad del llamado Batán Nuevo, ubicado en la parada de la Alhadra, para lo que llegó una mano al batán, lanzó una piedra y cerró y abrió las puertas de la casa ${ }^{52}$.

Los propietarios arrendaban los batanes a los pelaires, que eran los trabajadores encargados directamente de su explotación, y solían hacerlo por un período de tiempo breve, rara vez superior a los cuatro o cinco años, aunque en algún caso se documenten arrendamientos acordados por una o dos vidas. Fue costumbre frecuente la de arrendar o subarrendar la mitad o la tercera parte de un batán, a veces porque la propiedad solo mantenía dicha parte de posesión, a veces porque más de un pelaire compartía el uso de la misma maquinaria; y el importe de esos arrendamientos se percibía siempre en metálico. La elevación de las rentas pagadas por el alquiler de los batanes se aprecia con claridad a fines del siglo XV, probablemente en relación con el desarrollo de la industria textil de la ciudad y la capacidad de atracción de los paños de la comarca a que antes nos hemos referido; si entre 1460 y 1480 las rentas anuales se mantuvieron en cantidades que oscilaron en torno a los 3.000-4.000 mrs. de media, entre 1480 y1500 se elevaron hasta alcanzar cifras medias situadas entre 6.000-9.000 mrs. anuales, alcanzando en ocasiones los 10.000-12.000 mrs. (ver Cuadro 1) ${ }^{53}$.

Cuadro 1: Contratos de arrendamiento de batanes documentados en los protocolos notariales de la ciudad de Córdoba (años 1460-1500).

\begin{tabular}{|c|c|c|l|l|l|}
\hline AÑO & $\begin{array}{c}\text { IMPORTE } \\
\text { ARRENDA- } \\
\text { MIENTO }\end{array}$ & $\begin{array}{c}\text { IMPORTE } \\
\text { SUBARREN- } \\
\text { DAMIENTO }\end{array}$ & $\begin{array}{c}\text { EMPLAZA- } \\
\text { MIENTO }\end{array}$ & NOMBRE & PROPIETARIO \\
\hline 1463 & 3.500 & & San Julián & Luengo & Iglesia Mayor \\
\hline 1463 & & 3.600 & Cucarrón & Pequeño & Nuño Mejía \\
\hline 1467 & & 3.300 & Cucarrón & & Nuño Mejía \\
\hline 1468 & & 3.000 & Alcolea & Batanejo & Fadrique Manrique \\
\hline 1468 & 4.200 & & Cucarrón & & Nuño Mejía \\
\hline 1468 & & 2.800 & Cucarrón & & Nuño Mejía \\
\hline 1469 & & 3.600 & Alcolea & & \\
\hline 1469 & & 3.600 & Alcolea & Batanejo & Fadrique Manrique \\
\hline 1471 & & 4.200 & Cucarrón & & Nuño Mejía \\
\hline
\end{tabular}

o Montoro (pp. 122-123). En 1494 se citan, entre los bienes que poseía en Córdoba Juan Ayala, señor de Cebolla y Villalba, los batanes, aceñas, canal y pesquería en el río Guadalquivir, junto con la puente de Alcolea (1494.s.d., AHPCO, PNCO, Leg. 13669P, f. 471v).

52 1475.03.07, AHPCO, PNCO, Leg. 14114P, Cuad. 10, f. 4v; 1497.07.18, AHPCO, PNCO, Leg. 14136P, Cuad. 22, f. 176r.

${ }^{53}$ R. Córdoba, Molinos y batanes, p. 56. 
LOS BATANES HIDRÁULICOS DE LA CUENCA DEL GUADALQUIVIR

\begin{tabular}{|c|c|c|c|c|c|}
\hline 1471 & & 4.000 & Alcolea & Grande & $\begin{array}{l}\text { Iglesia Mayor/Juan } \\
\text { Ayala } \\
\end{array}$ \\
\hline 1471 & & 3.300 & Cucarrón & & Constanza Merlo \\
\hline 1471 & & 4.200 & Cucarrón & & \\
\hline 1475 & & 5.000 & San Julián & & Convento Sta. Inés \\
\hline 1476 & & 4.000 & Cucarrón & & Nuño Mejía \\
\hline 1476 & & 4.000 & Cucarrón & & Nuño Mejía \\
\hline 1477 & & 6.000 & $\begin{array}{l}\text { Puente } \\
\text { Mayor }\end{array}$ & & $\begin{array}{l}\text { Diego Gutiérrez de } \\
\text { los Ríos }\end{array}$ \\
\hline 1477 & & 3.300 & Alcolea & Grande & $\begin{array}{l}\text { Iglesia Mayor/Juan } \\
\text { Ayala } \\
\end{array}$ \\
\hline 1477 & & 6.000 & \begin{tabular}{|l|} 
Cucarrón \\
\end{tabular} & & Nuño Mejía \\
\hline 1482 & & 2.000 & Parias & & $\begin{array}{l}\text { Convento Sta. } \mathrm{M}^{\mathrm{a}} \\
\text { Dueñas }\end{array}$ \\
\hline 1484 & 3.000 & & San Julián & & Convento Sta. Inés \\
\hline 1484 & & 1.800 & Alhadra & & \\
\hline 1486 & & 10.000 & San Julián & Cortillo & Iglesia Mayor \\
\hline 1489 & & 10.500 & Alhadra & \begin{tabular}{|l|} 
Elvira \\
Brava \\
\end{tabular} & Alfonso de Mesa \\
\hline 1489 & 3.000 & & Cucarrón & & \\
\hline 1489 & & 9.000 & San Julián & Luengo & Iglesia Mayor \\
\hline 1489 & & 12.000 & San Julián & & \\
\hline 1490 & & 12.000 & San Julián & & \\
\hline 1490 & & 8.000 & Alhadra & Sta. María & Fernando de Cárcamo \\
\hline 1491 & 1.000 & & Pajares & Acémila & Orden de Calatrava \\
\hline 1491 & & 6.000 & Alhadra & $\begin{array}{l}\text { Agua } \\
\text { Caliente }\end{array}$ & Alcaide Donceles \\
\hline 1493 & 10.000 & & Casillas & & Pedro Fernández \\
\hline 1494 & & 16.000 & San Julián & & \\
\hline 1494 & & 8.000 & Alhadra & $\begin{array}{l}\text { Agua } \\
\text { Caliente }\end{array}$ & Alcaide Donceles \\
\hline 1495 & & 7.500 & San Julián & Cortillo & Iglesia Mayor \\
\hline 1495 & & 9.000 & Casillas & & Pedro Fernández \\
\hline 1495 & & 3.000 & Alhadra & & \\
\hline 1496 & & 6.000 & San Julián & Luengo & Iglesia Mayor \\
\hline 1496 & & 6.000 & San Julián & Cortillo & Iglesia Mayor \\
\hline 1496 & 8.000 & & Alhadra & \begin{tabular}{|l|}
$\begin{array}{l}\text { Agua } \\
\text { Caliente }\end{array}$ \\
\end{tabular} & Alcaide Donceles \\
\hline 1496 & & 9.000 & Alhadra & \begin{tabular}{|l|} 
Agua \\
Caliente
\end{tabular} & Alcaide Donceles \\
\hline 1496 & & 12.000 & San Julián & Cortillo & Iglesia Mayor \\
\hline 1496 & & 7.500 & San Julián & & $\begin{array}{l}\text { Garcí Méndez de } \\
\text { Sotomayor }\end{array}$ \\
\hline
\end{tabular}




\begin{tabular}{|l|l|l|l|l|l|}
\hline 1497 & & 3.600 & San Julián & & \\
\hline 1497 & 9.000 & Alhadra & $\begin{array}{l}\text { Agua } \\
\text { Caliente }\end{array}$ & Alcaide Donceles \\
\hline 1497 & & 5.000 & Cucarrón & & Tristán de Merlo \\
\hline 1499 & 7.500 & & San Julián & $\begin{array}{l}\text { Luengo/ } \\
\text { Cortillo }\end{array}$ & Iglesia Mayor \\
\hline 1499 & & 6.000 & San Julián & Cortillo & Iglesia Mayor \\
\hline 1500 & & 6.000 & San Julián & Luengo & Iglesia Mayor \\
\hline
\end{tabular}

Una práctica muy común, que se documenta en numerosas ocasiones en los contratos notariales de la época, fue la del subarrendamiento, realizado por los mismos pelaires que habían tomado la instalación a renta. Éste solía realizarse por un período de tiempo más breve que el del arrendamiento principal, que oscilaba entre los seis meses y el año, y por una renta algo superior a la acordada en aquél; el batán del Agua Caliente, arrendado por 8.000 mrs. en 1496, pagó en subarrendamiento ese mismo año 9.000 mrs.; en mayo de 1499 el pelaire Martín García arrendó la mitad de los batanes Cortillo y Luengo por 3.750 mrs. de renta anual cada uno y los subarrendó, con fecha 11 de junio del mismo año y 31 de enero de 1500 , a otros pelaires por renta anual de $6.000 \mathrm{mrs}$., obteniendo así un interesante margen de ganancia ${ }^{54}$.

\subsection{Piezas y componentes de la maquinaria}

Los componentes técnicos y el instrumental utilizado por los batanes de la cuenca del Guadalquivir a fines de la Edad Media nos resultan bien conocidos gracias a la documentación notarial que se conserva desde mediados del siglo XV. En primer lugar, hay que tener en cuenta que el sistema propulsor del mecanismo, es decir, la rueda de paletas golpeada por la corriente que transmite su movimiento de rotación al eje al que se halla conectada, fue idéntico en los batanes y en las aceñas harineras, de forma que conocemos bien los nombres y funciones de sus componentes gracias a los datos obtenidos en contratos pertenecientes a ambos tipos de instalación. A partir de aquí, la maquinaria era completamente distinta, pues en los batanes el eje no iba unido a la entruesga o rueda dentada, y ésta a su vez al carro o linterna (cilindro de varas), sino articulado mediante un árbol de levas encargado de elevar los mazos del batán; sin embargo, contamos con numerosas referencias documentales, datadas en la segunda mitad del siglo $\mathrm{XV}$, a distintas piezas de la maquinaria. Y, sobre todo, con buenos referentes bibliográficos gracias a las investigaciones llevadas a cabo sobre batanes tradicionales de la Península Ibérica, bien porque se conserva sobre ellos abundante documentación histórica, bien por haberse mantenido en uso hasta mediados del pasado siglo, pero que en cualquier caso permiten establecer los oportunos paralelos; entre ellos, los batanes de Ossa de Montiel, Albacete, estudiados por José Sánchez Ferrer; el de La Horcajada, en Ávila, por Luis Cortés Vázquez; el de Ledantes en Cantabria, por Alberto Díaz y Fernando Sopeña; o el de Lacort en Huesca, por Severino Pallaruelo ${ }^{55}$.

54 R. Córdoba, Molinos y batanes, pp. 55-56; el primer arrendamiento de los batanes de San Julián en 1499.05.10, AHPCO, PNCO, Leg. 14138P, Cuad. 2, f. 75v, y los subarrendamientos en 1499.06.11, AHPCO, PNCO, Leg. 14138P, Cuad. 14, f. 1r y 1500.01.31, AHPCO, PNCO, Leg. 14139P, Cuad 5, f. 25r.

55 J. Sánchez, Los batanes, pp. 101-130; L. Cortés, El batán, pp. 21-31; A. Díaz, F. Sopeña, El batán, pp. 277-294. 
Igualmente, es importante señalar que, si bien hasta la fecha no hemos localizado ningún aprecio o relación de bienes perteneciente al instrumental de un batán fechado en los siglos XV o XVI, disponemos de varios inventarios datados en la primera mitad del siglo XVIII que describen pormenorizadamente los componentes de batanes ubicados en el río Guadalquivir; como quiera que los nombres de las piezas utilizadas en estos ingenios no variaron en absoluto entre el final de la Edad Media y el siglo XIX (al igual que en el caso de las aceñas, se siguieron usando batanes de idénticos componentes y características hasta esa centuria), entendemos que es perfectamente legítimo hacer uso de la "historia regresiva" y utilizar las menciones del instrumental que aparecen en esos aprecios del siglo XVIII puesto que coinciden, en todos los casos, con la nomenclatura que observamos en la documentación bajomedieval. Los aprecios dieciochescos que utilizaremos para ello fueron realizados en dos de los batanes situados en el término municipal de Montoro, en concreto los batanes de la Hoz y de Fernando Alonso, y fueron realizados el primero de ellos por Alonso Canales Bermejo, aladrero vecino de Montoro, y el segundo por Andrés de Cárdenas, Alonso García Polo, Juan Canales y Pedro García, apreciadores nombrados por la propiedad y los arrendatarios, en los años 1728 y 1735 respectivamente ${ }^{56}$.

Los batanes se hallaban instalados en las paradas, presas o azudas, tanto del río Guadalquivir como del Guadajoz, donde también se ubicaron aceñas, molinos y norias. Estas presas, que cortaban la corriente para encauzar el agua hacia las orillas del río, a fin de conducirla y hacerla transitar por los canales donde se disponían las ruedas hidráulicas, pertenecieron a la tipología de las llamadas "estacadas", es decir, obras sostenidas sobre estacas de madera hincadas en el lecho de la corriente fluvial, que posteriormente se unían y rellenaban mediante ripio, cascajo y cal, formando una obra de mampostería. Sobre su construcción y reparación en los últimos años de la Edad Media disponemos de distintos testimonios, como el acuerdo firmado en junio de 1504 por Sancho González del Cañaveral, como tutor de los hijos de Pedro Fernández de la Membrilla, para liquidar cuentas con Juan Jiménez del Portillo, mayordomo de la hacienda de los dichos menores, entre las que se citaban 1.463 mrs. que había gastado en la azuda del batán, de la piedra, maestros, cal y estacas que en ellas se había puesto para su reparación ${ }^{57}$.

La instalación solía consistir en un edificio abovedado a uno de cuyos costados se habilitaba el canal para el paso del agua. En dicho canal, con una anchura en torno al metro o metro y medio, iba emplazada la rueda hidráulica vertical; junto a él existía un canal aliviadero por donde el agua discurría de continuo. Cuando se deseaba poner en marcha la rueda, y con ella el mecanismo del batán, el aliviadero se cerraba mediante una compuerta y el canal se abría elevando otra similar; lógicamente, para detener la maquinaria se efectuaba la operación inversa. Esta compuerta, que permitía la entrada y regulaba el paso del agua por el canal de la rueda, fue conocida por el nombre de aguatocho en todas las instalaciones hidráulicas de la época ${ }^{58}$.

56 1728.04.13, AHPCO, PNMO, Leg. 7358P, ff. 43r-43v; 1735.05.25, AHPCO, PNMO, Leg. $7361 \mathrm{P}$, ff. $267 \mathrm{v}-268 \mathrm{r}$.

57 1504.06.14, AHPCO, PNCS, Leg. 4954, f. 173r. Para conocer la tipología, técnicas de construcción y labores de reparación llevadas a cabo en las azudas de los ríos de la cuenca durante el período histórico que nos ocupa, R. Córdoba et al., Puertos, pp. 63-78; R. Córdoba et al., Los molinos, pp. 12-18 del CD.

${ }^{58}$ En febrero de 1484 Luis López, un aladrero vecino de Córdoba, acordaba hacer de nuevo para el pelaire Luis López el Batán Grande del Puente de Alcolea, «sacando rueda, aguatocho y eje, que lo dará el pelaire» (1484.02.25, AHPCO, PNCO, Leg. 14122P, Cuad.9, f. 39v); el aguatocho con su colgadero es valorado en 24 reales en el aprecio del batán de la Hoz (1728.04.13, AHPCO, PNMO, Leg. 7358P, f. 43r) y en 27 reales en el de Fernando Alonso (1735.05.25, AHPCO, PNMO, Leg. 
La rueda se articulaba en torno a un eje de sección circular al que se sujetaban cuatro brazos de madera en forma de aspa, denominados cruces. Las cruces sustentaban las piezas curvas que, unidas entre sí, formaban el perímetro de la rueda o circunferencia y que eran llamadas camones. Las cruces constituían un elemento capital de la rueda, puesto que transmitían al eje el movimiento obtenido mediante el impacto del agua en las paletas. Para ello, en los camones se colocaban los álabes o paletas de la rueda, piezas planas de madera sobre las que golpeaba el agua para imprimir a rueda y eje el movimiento de rotación circular ${ }^{59}$. Los camones son denominados cambones en batanes de Ávila, Asturias y Cantabria; muchas de las ruedas de batanes tradicionales del norte de la Península llevaron una sola línea de camones en los que se insertaban directamente los álabes, mientras que las usadas en los batanes del Guadalquivir parecen haber llevado una doble línea de camones que abrazaban los álabes por sus lados internos, reforzando su solidez $z^{60}$.
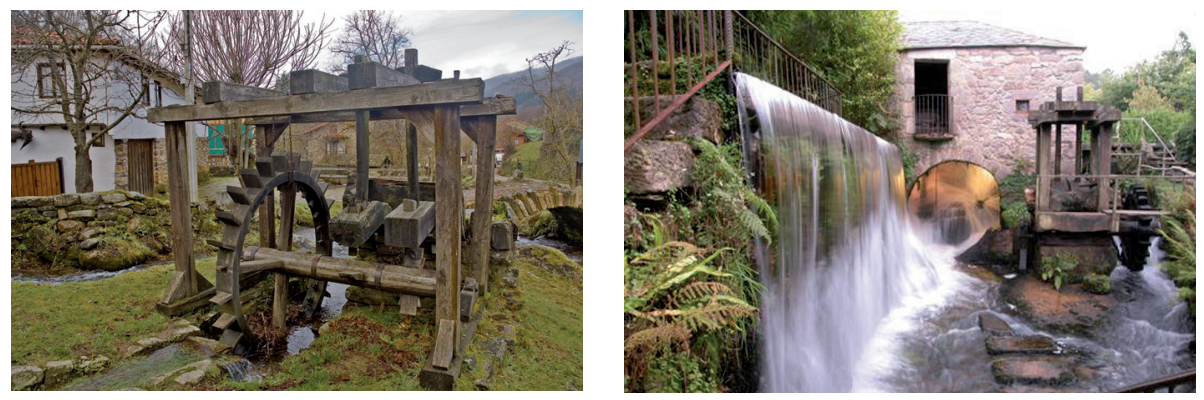

Fig. 4. Batanes como éstos de Aniezo, en Cantabria (fot. jroblear), y de Alfoz, en Lugo (fot. Finca Galea), se conservan con la misma fisonomía y componentes a los que se documentan para época bajomedieval en la cuenca del Guadalquivir.

7361P, f. 267v). Sobre el uso de los aguatochos en los canales de norias y molinos, R. Córdoba et al., Puertos, pp. 79-80; R. Córdoba et al., Los molinos, pp. 21-22 del CD. Esta pieza aparece con el mismo nombre, «aguatoju», en batanes asturianos (G. Morís, Ingenios, p. 32).

${ }^{59}$ Ya hemos visto, en el documento citado en la anterior nota, cómo el aladrero Luis López acordaba con un pelaire homónimo hacer de nuevo el Batán Grande del Puente de Alcolea, «sacando rueda, aguatocho y eje» (1484.02.25, AHPCO, PNCO, Leg. 14122P, Cuad.9, f. 39v); cuando en 1493 el trapero de Córdoba Pedro Fernández acordó con el albañil Andrés Fernández la realización de ciertas obras en las aceñas de Casillas, especificó en el contrato que el citado albañil había «de hacer un hueco en el mismo canal, entre rueda y rueda, de siete pies en ancho para entrar por una puerta que se ha de hacer en el batán bajo» (1493.07.31, AHPCO, PNCO, Leg. 13669P, f. 123v); la rueda «encabalgada», es decir, colocada en el canal y unida al eje, lista para trabajar, fue apreciada en 150 reales en el batán de la Hoz (1728.04.13, AHPCO, PNMO, Leg. 7358P, f. 43r) y en 120 en Fernando Alonso (1735.05.25, AHPCO, PNMO, Leg. 7361P, f. 267v). Sobre los rasgos y componentes de las ruedas hidráulicas usadas en aceñas y batanes, R. Córdoba et al., Los molinos, pp. 25-27 del CD.

${ }^{60}$ Numerosos dibujos y fotografías ilustran la composición de estas ruedas, aunque las usadas en el Guadalquivir debieron ser similares a la del batán de Lumbrales, en Salamanca, fotografiado en el artículo de L. Cortés, El batán, p. 25. Cita de cambones en G. Morís, Ingenios, p. 32; L. Cortés, El batán, p. 27. 
El eje consistía en un tronco enterizo, de diámetro y longitud variable según las necesidades específicas de cada instalación, dispuesto en horizontal y que se hallaba sustentado, como es lógico, en sendas zapatas situadas a cada uno de sus extremos; una iba colocada en la parte exterior del canal, al costado externo de la rueda hidráulica, y la otra en la parte opuesta a donde se hallaban los mazos y maquinaria del batán. Las zapatas estuvieron integradas por dos piezas, cabezal y tejuelo, sobre las que giraba la punta del eje, un vástago horizontal obtenido mediante inserción de una barra o punta de hierro en el lateral del tronco; este hierro, llamado aguijón, que sobresalía del eje en torno a los 15-20 cm., quedaba reforzado por diferentes sortijas o ceños (aros) de hierro que apretaban los extremos del eje para asegurar la fijación del aguijón e impedir que el tronco se abriera ${ }^{61}$. En el batán de La Horcajada, Ávila, y en los batanes albacetenses de Ossa de Montiel, los espigos de hierro que se incrustan en cada extremo del eje y que permiten su giro reciben el similar nombre de guijos; en cambio, esta misma pieza recibe tanto en el batán de Lacort, en Huesca, como en los batanes documentados en Asturias por Gonzalo Morís el nombre de corrones o gorriones (gorrones, nombre también recibido por el eje de la maza sobre el que gira el rodezno y apoya en la rangua en los molinos de cubo) ${ }^{62}$. El uso de aros o ceños de hierro para asegurar el guijo o gorrón se documenta igualmente en los batanes de Ledantes y Lacort (en este segundo caso bajo el nombre de zarcoles) ${ }^{63}$.

Todos estos componentes del sistema de aprovechamiento hidráulico fueron de uso común tanto en aceñas como en batanes, puesto que sirvieron para conseguir el aprovechamiento de la energía hidráulica. Los que vamos a ver a continuación fueron, en cambio, utilizados para convertir el movimiento rotatorio proporcionado por el conjunto eje-rueda en otro de carácter lineal, vertical (arriba/abajo) u horizontal (adelante/atrás). Para ello se utilizó el llamado árbol de levas, sistema en el que unas levas o cuñas de madera, que seguían el mismo recorrido circular del eje, enganchaban durante un trayecto de su recorrido con otra pieza de madera que, al soltarse tras el paso de la leva, conseguía elevar o hacer descender un tercer componente y convertir de esa forma en lineal el movimiento circular ${ }^{64}$.

Para ello el eje del batán dispuso, en la zona media del tronco, de dos piezas de madera que atravesaban el eje llamadas liebas (levas) que golpeaban, en algún momento de su rotación, sobre otras conocidas por el nombre de sobarbos, que iban unidas directamente a los brazos o astiles de donde colgaban los mazos del batán. La leva elevaba a su paso el sobarbo y éste tiraba hacia atrás del mazo y de su astil, de

\footnotetext{
${ }^{61}$ Repetimos la cita del contrato por el que Luis López acordaba la construcción del Batán Grande del Puente de Alcolea, «sacando rueda, aguatocho y eje» (1484.02.25, AHPCO, PNCO, Leg. 14122P, Cuad.9, f. 39v); o la realizada en 1573 en los batanes de Martos, cuando se menciona una pequeña noria que se movía «con el eje de la rueda principal del mismo batán» (1573, AHN, AHJT, Legajo 43249). Cuando el pelaire cordobés Francisco Sánchez subarrendó a Juan Ruiz la mitad de un batán lo hizo con la condición de que «si se quebrare alguna sortija o aguijón del batán» Juan Ruiz debía abonar la mitad de su coste (1482.01.23, AHPCO, PNCO, Leg. 14108P, Cuad. 7, f. 23v). Los cabezales y tejuelos del batán de la Hoz fueron apreciados en 16 reales y sus sortijas y aguijones en 64 (1728.04.13, AHPCO, PNMO, Leg. 7358P, f. 43r), en tanto que los mismos componentes fueron apreciados en 14 y 66 reales, respectivamente, en el de Fernando Alonso (1735.05.25, AHPCO, PNMO, Leg. 7361P, f. 267v). Sobre las características de los ejes de aceña en los molinos de la cuenca, R. Córdoba et al., Los molinos, pp. 27-28 del CD; R. Córdoba, Los molinos, p. 297.

${ }^{62}$ L. Cortés, El batán, p. 27; J. Sánchez, Los batanes, p. 130; S. Pallaruelo, Los molinos, p. 204; G. Morís, Ingenios, p. 32.

${ }^{63}$ L.A. Alonso, La pisa, p. 15; S. Pallaruelo, Los molinos, p. 204.

${ }^{64}$ Sobre la invención del árbol de levas y su aplicación a la rueda hidráulica vertical en la Edad Media, T.S. Reynolds, Stronger, pp. 79-90.
} 
forma que cuando se soltaba éstos caían por gravedad, consiguiendo así un movimiento pendular. Ambas piezas constituían la clave del árbol de levas, es decir, del sistema que permitía transformar el sentido del movimiento $y$, aunque las levas iban acopladas al eje del batán mientras que los sobarbos lo hacían a los astiles de sus mazos, suelen aparecer siempre mencionadas juntas en la documentación, lo cual tiene todo el sentido ya que ambos componentes ponían en relación el sistema de aprovechamiento hidráulico con la maquinaria específicamente diseñada para el golpeo de los paños ${ }^{65}$. Los sobarbos, definidos por José Sánchez como piezas de madera o hierro sobre las que empujaban las levas y que sobresalían por la parte inferior de los mazos y las levas o piezas de madera montadas perpendicularmente al eje del árbol que desplazaban los mazos recibían idéntica denominación en los batanes tradicionales de la zona de Albacete y en el batán de La Horcajada (Ávila), mientras que en Cantabria fueron conocidos por el de levas y mazorgas ${ }^{66}$.

La maquinaria del batán propiamente dicho estaba integrada por dos partes bien diferenciadas en componentes y función: los grandes mazos (generalmente dos por batán) suspendidos de astiles que golpeaban el paño y la pila o artesa donde éste era depositado para su golpeo. Los mazos se hacían colgar de una estructura de madera compuesta por cuatro pies derechos y reforzada por travesaños en su parte superior para el soporte de los mazos; esta estructura ha sido conocida históricamente en los batanes de la cuenca del Guadalquivir por el nombre del castillo. Estaba constituido por cuatro maderos o pies derechos unidos por su parte superior a otros colocados de forma horizontal para darle solidez ${ }^{67}$. También recibía este nombre la "estructura de madera que sostenía y articulaba los mazos" en los batanes de Albacete y en el de La Horcajada de Ávila, mientras que fue conocida por el nombre del potro en los asturia$\operatorname{nos}^{68}$. Los pies del castillo, o postes verticales, han recibido nombres diferentes en los batanes de cada comarca: pies en La Horcajada, machones en Ossa de Montiel, postes en Ledantes; como lo han hecho los maderos horizontales que los unían por su parte superior: guías en Lacort, castilletes en La Horcajada, caderas en Ossa, llaves en Ledantes $^{69}$. Pero en ningún caso los hemos hallado diferenciados del nombre genérico de castillo en los batanes del Guadalquivir.

Los maderos que integraban el castillo se sustentaban a su vez sobre las soleras, tablones fuertemente anclados en el terreno que sirvieron para soportar toda

\footnotetext{
${ }^{65}$ Francisco Sánchez, pelaire, subarrienda a Juan Ruiz la mitad de un batán en la parada de Parias, por renta de $1000 \mathrm{mrs}$. anuales y un par de liebas y sobarbos (1482.01.23, AHPCO, PNCO, Leg. 14108P, Cuad. 7, f. 23v); Alfonso Ruiz, vecino de Lucena, reconocía deber al pelaire Diego Ruiz, mil mrs. que recibió para dárselos en madera de levas y sobarbos para batán, y otorgaba pagárselos en veinte cargas de la dicha madera (1488.06.26, AHPCO, PNCO, Leg. 14126P, Cuad. 5, f. 4v). «Cuatro liebas que sirven» fueron valoradas en el batán de la Hoz en 24 reales y «dos liebas y tres sobarbos» en 15 (1728.04.13, AHPCO, PNMO, Leg. 7358P, f. 43r), y «las liebas» en 7 reales en el de Fernando Alonso (1735.05.25, AHPCO, PNMO, Leg. 7361P, f. 267v).

${ }^{66}$ J. Sánchez, Los batanes, p. 130; L. Cortés, El batán, p. 28; A. Díaz, F. Sopeña, El batán, p. 282; Luis Alberto Alonso, autor de la restauración del batán de Ledantes, afirma que las mazorcas eran las levas, en tanto que los sobarbos recibían el nombre de brazuelos, pieza introducida en la caja del mazo sobre la que golpea la mazorga (L.A. Alonso, La pisa, p. 15).

67 «El castillo» aparece valorado en 56 reales en el batán de la Hoz (1728.04.13, AHPCO, PNMO, Leg. 7358P, f. 43r), y en 30 reales en el de Fernando Alonso (1735.05.25, AHPCO, PNMO, Leg. 7361P, f. 267v).

${ }^{68}$ J. Sánchez, Los batanes, p. 130; L. Cortés, El batán, p. 29; G. Morís, Molinos, vol. I, p. 207.

${ }^{69}$ L. Cortés, El batán, p. 29; J. Sánchez, Los batanes, p. 130; A. Díaz, F. Sopeña, El batán, p. 282; S. Pallaruelo, Los molinos, p. 204.
} 
la estructura y evitar su desplazamiento ${ }^{70}$. Las soleras son definidas por José Sánchez Ferrer como grandes maderos colocados en la parte inferior del batán sobre los que se montaba toda la estructura; en el batán de Ledantes se llamaban almanques los dos maderos que constituían la base para los postes del castillo, iban unidos por la parte delantera a otro colocado a través llamado solera, y se disponían sepultados bajo tierra por la parte trasera del batán para contrarrestar los golpes de los mazos cuando la máquina se hallaba en funcionamiento ${ }^{71}$.

De la parte superior del castillo se hacían colgar los mazos mediante sujeción en unas largas varas de madera conocidas por el nombre de hastiales, reforzadas en su parte externa por los sobrehastiales, especie de cuñas cuya finalidad principal era la de ajustar la altura y disposición del mazo en el hastial ${ }^{72}$. Estas piezas se denominan en los batanes de Ossa astiles (definidos por José Sánchez como mangos o varas del mazo) y en el de Ledantes, tirantes (brazos de donde cuelgan los mazos) ${ }^{73}$.

Para colgar hastiales y mazos se disponían tres maderos que, por la parte superior del castillo, unían el travesaño colocado en la parte delantera con el ubicado en la trasera; eran los llamados puentes, sobre cuya parte superior se apoyaban las perchas o piezas pasantes de madera de las que colgaban directamente los hastiales y que posibilitaban su basculamiento ${ }^{74}$. Estos travesaños fueron conocidos también por el nombre de puentes en el batán de La Horcajada, cargaderos en Ledantes, guías en Lacort; y las perchas a las que se sujetaba el extremo superior del hastial fueron llamadas yuguetos en el batán de Ledantes ${ }^{75}$.

Los mazos eran estructuras cúbicas de madera que colgaban de la parte inferior de los hastiales; solían tener forma alargada, rematando en superficie escalonada o cóncava por la parte que golpeaba el paño en la pila y en forma recta por la cara posterior ${ }^{76}$. En aquellos batanes tradicionales donde han sido documentados, solían alcanzar un peso considerable, de hasta 70-90 kg., y se hallaban acoplados al hastial gracias a un orificio efectuado en su parte central, donde ajustaban sobrehastial

${ }^{70}$ Formando parte del testamento del aladrero Pedro Feo se citan un par de soleras nuevas (1475.05.28, AHPCO, PNCO, Leg. 14114P, Cuad. 8, f. 2r); en 1497 el trapero Francisco Fernández traspasó al pelaire Juan Rodríguez dos medios batanes en la parada de Cucarrón, acordando que «el batán que ahora está por hacer tiene una solera cortilla, que se ha de encadenar o dejar otra solera más larga» (1497.12.28, AHPCO, PNCO, Leg. 14136P, Cuad. 16, f. 10v). Tres soleras fueron apreciadas en 50 reales en el batán de la Hoz (1728.04.13, AHPCO, PNMO, Leg. 7358P, f. 43r), en tanto que las soleras del batán de Fernando Alonso lo fueron en 32 reales (1735.05.25, AHPCO, PNMO, Leg. 7361P, f. 267v).

${ }^{71}$ J. Sánchez, Los batanes, p. 130; A. Díaz, F. Sopeña, El batán, p. 282.

72 Hastiales y sobrehastiales son valorados en 80 reales, y un hastial en 10 , en el batán de la Hoz (1728.04.13, AHPCO, PNMO, Leg. 7358P, f. 43r) y en 50 reales en el de Fernando Alonso (1735.05.25, AHPCO, PNMO, Leg. 7361P, f. 267v).

${ }^{73}$ J. Sánchez, Los batanes, p. 130; A. Díaz, F. Sopeña, El batán, p. 282.

${ }^{74}$ Perchas y puentes fueron apreciados en 12 reales en el batán de la Hoz (1728.04.13, AHPCO, PNMO, Leg. 7358P, f. 43v) y en 7 y 24 reales los de las pilas de adentro y de afuera, respectivamente, del batán de Fernando Alonso (1735.05.25, AHPCO, PNMO, Leg. 7361P, f. 267v).

${ }^{75}$ L. Cortés, El batán, p. 29; A. Díaz, F. Sopeña, El batán, p. 282; S. Pallaruelo, Los molinos, p. 204.

${ }^{76}$ Cuando el aladrero Luis López acordó con el pelaire homónimo la renovación del Batán Grande del Puente de Alcolea, se comprometió a «hacer los mazos de dos palmos y una mano de tabla», es decir, con unas dimensiones de $50 \mathrm{~cm}$. de longitud (1484.02.25, AHPCO, PNCO, Leg. 14122P, Cuad.9, f. 39v). Los mazos encabalgados fueron apreciados en 166 reales en el batán de la Hoz (1728.04.13, AHPCO, PNMO, Leg. 7358P, f. 43r) y en 86 y 67 reales los de las pilas de adentro y de afuera, respectivamente, del batán de Fernando Alonso (1735.05.25, AHPCO, PNMO, Leg. 7361P, f. $267 \mathrm{v})$. 
y sobarbo. Los mazos fueron, qué duda cabe, los grandes protagonistas de esta parte de la maquinaria del batán, dado que en realidad el resto de componentes (liebas y sobarbos, castillo y soleras, hastiales y sobrehastiales, puentes y perchas) se hallaban al servicio de ellos y fueron diseñados expresamente para obtener su movimiento y la capacidad de golpear las telas durante el proceso de abatanado.

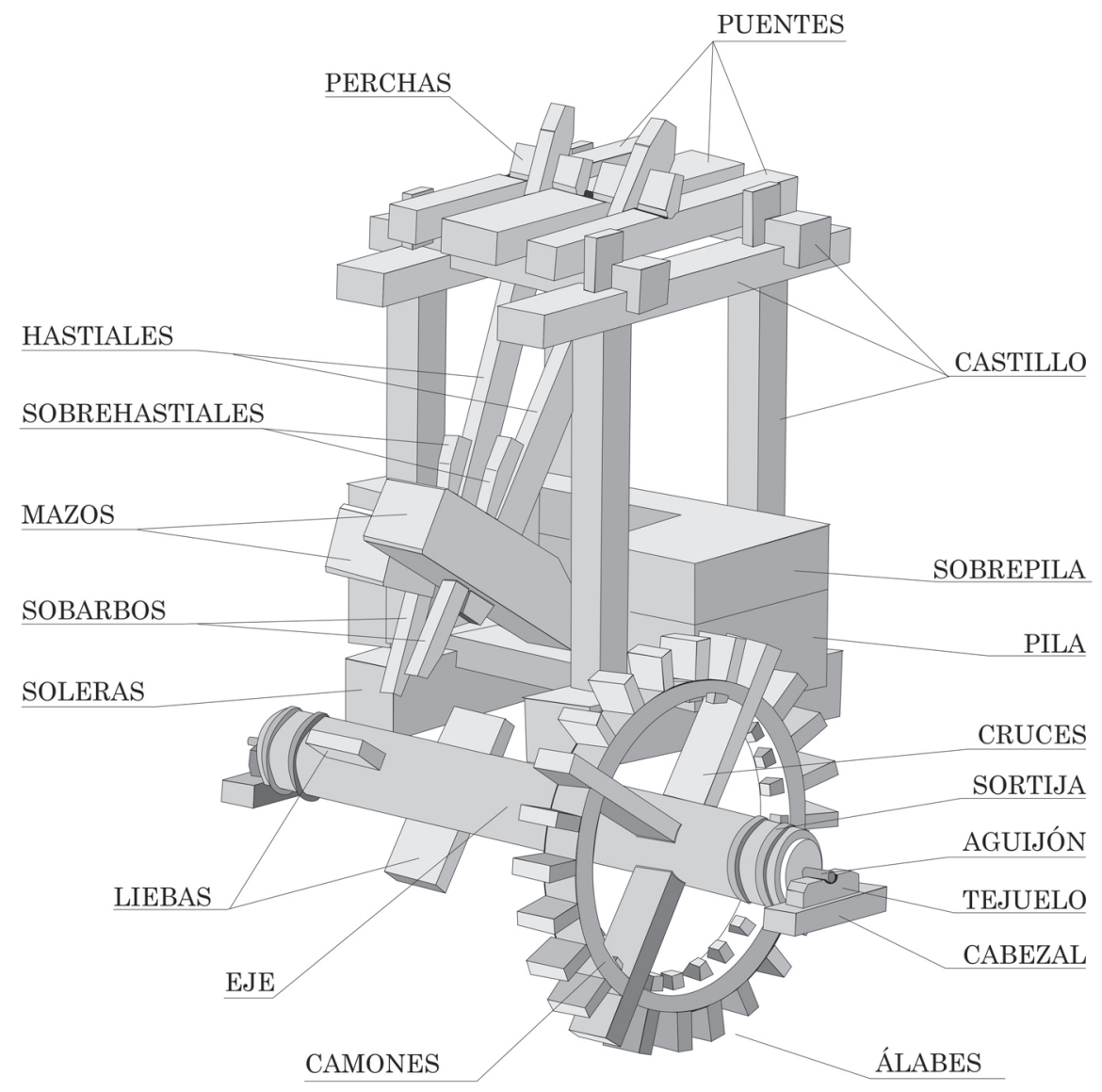

Fig. 5. Esquema de un batán tradicional, con indicación del nombre recibido por sus distintos componentes en la cuenca del Guadalquivir (basado en un diseño 3D por ordenador de José Ignacio Rojas-Sola).

Pero la segunda parte destacada de la estructura del batán fue la pila, una artesa de madera recortada en forma de L por el interior, lo que permitía obtener una superficie horizontal en su parte inferior para depositar el paño y otra vertical al fondo 
para servir de apoyo al tejido durante el golpeo de los mazos. En numerosos batanes tradicionales la pila estuvo formada por una gran sección de tronco de árbol recortada por una de sus caras ${ }^{77}$, pero en otros casos se obtuvo mediante ensamblaje de diversos maderos escuadrados con la forma adecuada, como se documenta en los casos de los batanes de Mosquetín, en Vimianzo (La Coruña), y de Villava, en Navarra ${ }^{78}$. Es difícil establecer con seguridad la modalidad de pila que fue adoptada por los batanes de la cuenca del Guadalquivir en la época estudiada, entre otras cosas porque la pila, como el resto de componentes, nunca aparece descrita con detalle y porque es probable que fuera usada una diversidad de soluciones según los casos. De cualquier forma, es frecuente que se citen dos componentes, la pila y la sobrepila, como piezas distintas aunque vinculadas entre sí, lo que nos lleva a pensar que la estructura debía de estar integrada por varios maderos mediante cuyo ensamblaje se conseguía la forma de cubeta $^{79}$. En el batán de La Horcajada, Ávila, existe delante de la pila una tabla atravesada llamada "antepecho" en la que tropiezan los sobarbos de los mazos para detener su marcha en el límite preciso y no golpear con excesiva rudeza el paño, pieza que quizás se pueda vincular con el batidor mencionado en los aprecios de los batanes de Fernando Alonso de $1735^{80}$.

Mientras el paño era golpeado por los mazos en la pila, debía de ser regado tanto para facilitar la mezcla con las arcillas astringentes que lograban su limpieza y enfurtido, como para evitar su excesivo calentamiento y rotura. Para ello existió en todos los batanes un canalillo largo de madera llamado canaleja que se encargaba de aportar agua hasta la pila y, en muchos casos, también hasta los aguijones del eje para empapar de agua cabezales y tejuelos y contrarrestar el calor que producen los aguijones al girar mientras está trabajando el batán ${ }^{81}$. En la mayor parte de batanes tradicionales, el agua utilizada para este cometido se tomaba del canal que transportaba el agua hasta la rueda, habilitando una salida directa en su recorrido. Sin embargo, en los batanes del Guadalquivir documentados entre el siglo XV y el XVIII las canalejas aparecen vinculadas al uso de norietas o pequeñas norias de cangilones que extraían del lecho fluvial agua para este fin. En el aprecio del montoreño batán de la Hoz, fechado en 1728, se valoran la ñoreta con sus cangilones en 70 reales, el dornajo (artesa donde vertían el agua los cangilones) y peón (árbol o eje vertical de la noria) en 10 reales y la puente de madera (tabla en la que se apoya el gorrón o vástago sobre el que gira el peón) en 20 reales; ñoreta y dornajo vuelven a ser citados en los aprecios de las pilas de adentro y de afuera de los batanes de Fernando Alonso en $1735^{82}$. Pero el

\footnotetext{
${ }^{77}$ Así se documenta en batanes como los de Alfoz (Lugo), Aniezo (Cantabria), o en el restaurado batán de las aceñas de Olivares en Zamora. En el batán de Ledantes el tronco que forma la pila recibe el nombre de «peju» (A. Díaz, F. Sopeña, El batán, p. 282); y en batanes asturianos, donde igualmente la pila suele consistir en un grueso tronco labrado por una de sus caras, es llamada «imina» (G. Morís, Ingenios, p. 32).

78 J.M. Vázquez-Varela, M. Villarino, M. Cabana, Batanes; D. Alegría, Molino.

${ }^{79}$ Cuando el aladrero Luis López acordó con el pelaire homónimo la renovación del Batán Grande del Puente de Alcolea, se comprometió a «hacer la pila de cuadra de tres palmos», es decir, con unas dimensiones en torno a los $60 \mathrm{~cm}$. (1484.02.25, AHPCO, PNCO, Leg. 14122P, Cuad.9, f. 39v). Pila, sobrepila y canaleja fueron apreciadas en 100 reales en el batán de la Hoz (1728.04.13, AHPCO, PNMO, Leg. 7358P, f. 43r), mientras que pila, sobrepila, batidor y canaleja lo fueron en 74 reales en las dos pilas del batán de Fernando Alonso (1735.05.25, AHPCO, PNMO, Leg. 7361P, f. 267v).

${ }^{80}$ L. Cortés, El batán, p. 29 y véase también nota anterior.

${ }^{81}$ La pieza aparece con el nombre de canaleja en los batanes del Guadalquivir y en el abulense de La Horcajada (L. Cortés, El batán, p. 27).

82 1728.04.13, AHPCO, PNMO, Leg. 7358P, f. 43r; 1735.05.25, AHPCO, PNMO, Leg. 7361P, f. $267 \mathrm{v}$.
} 
uso de este sistema para proveer de agua a los batanes está documentado desde mucho antes. En 1573, durante la construcción de los batanes del molino de Martos, hallamos mencionada la instalación de pequeñas norias elevadoras de agua -denominadas norietas- en dos de las pilas ${ }^{83}$.

Si la pila y sus complementos (sobrepila, batidor, canaleja y norieta) completan las piezas o componentes que integraban la maquinaria del batán, es necesario añadir que en el interior de los batanes, es decir, de los edificios que albergaban esta función, los pelaires dispusieron también de numerosas herramientas y utillaje de mano, parte del cual fue utilizado para la propia labor de abatanado y tratamiento de los paños, y parte como auxiliar para la reparación y mantenimiento de la maquinaria. Entre los elementos que formaban el primer grupo, es decir, aquellos destinados a facilitar las operaciones que debían ser realizadas sobre los paños, podemos citar las calderas donde se obtenía el agua caliente necesaria para el lavado del paño en algunas fases del proceso ${ }^{84}$; las perchas o tiradores donde eran colgados los paños para ser cardados a la percha, estirados y secados -situadas en el interior de la casa del batán o en alguna dependencia o edificio anejo para uso de los bataneros ${ }^{85}-\mathrm{y}$, en relación con dicha operación, los bayartes y palmares de cardón utilizados para cardar ${ }^{86}$; y los contenedores o recipientes habilitados para contener greda, como esas casillas donde se tiene la greda que aparecen en los batanes de Martos en 1573 o los tinajones inventariados en el interior de algunos batanes ${ }^{87}$. Otros elementos que pudieron ser empleados para estas operaciones auxiliares son el escurridor, los dos alcayates y el caballo para la ropa citados en el batán de la Hoz en $1728^{88}$.

Entre los que forman el segundo grupo y que no estaban relacionados de manera directa con el proceso de abatanado, sino con la actividad cotidiana de los pelaires en el interior de estas instalaciones, destacan por encima del resto las herramientas de carpintería destinadas a la reparación de la maquinaria ${ }^{89}$, pero también elementos de uso cotidiano como muebles de mesa y banco, puertas del batán, candiles para la iluminación, harneros y cedazos, cadenas, palos, sartenes y un largo etcétera

83 1573, AHN, AHJT, Legajo 43249, s.f. Cit. J. Ortiz, Transformación, p. 237.

${ }^{84}$ En julio de 1468 dos pelaires de Córdoba, Juancho Vizcaíno y Juan Díaz, traspasaron a Martín de Úbeda, vecino en la collación de San Pedro, la tercera parte del batán que tenían a renta de Nuño Mejía en la parada de Cucarrón, con la parte de casa y caldera a él perteneciente, por tiempo de un año y renta de 1400 mrs. (1468.07.07, AHPCO, PNCO, Leg. 14106P, Cuad. 2, f. 164r).

${ }^{85}$ En junio de 1469 Martín Sánchez de Úbeda, pelaire vecino de Córdoba, subarrendaba a Lope Ruiz la tercera parte del batán llamado El Batanejo con condición de que «pueda poner percha y astero en las casas del dicho batán, donde entre ellos fuere convenido» (1469.06.24, AHPCO, PNCO, Leg. 14107P, Cuad. 16, f. 29r); dos perchas y dos tableros se citan entre el instrumental que el pelaire Juan Rodríguez recibió del trapero Francisco Fernández de Torrijos al hacerle traspaso de dos medios batanes que tenía a renta (1497.12.28, AHPCO, PNCO, Leg. 14136P, Cuad. 16, f. 10v).

${ }^{86}$ Un bayarte con ochenta pares de palmares y diez millares de cardón, valorado cada millar en 118 mrs., aparecen entre el instrumental del batán de la parada de Cucarrón citado en la nota anterior (1497.12.28, AHPCO, PNCO, Leg. 14136P, Cuad. 16, f. 10v); tres cajas de bayarte, valoradas en 50 reales, y 413 pares de palmares armados, valorados en 827 reales, en el batán de la Hoz (1728.04.13, AHPCO, PNMO, Leg. 7358P, f. 43v).

${ }^{87}$ Un tinajón se cita entre los bienes del batán de la parada de Cucarrón (1497.12.28, AHPCO, PNCO, Leg. 14136P, Cuad. 16, f. 10v) y ollas y dornillo valorados en 8 reales entre los del batán de la Hoz (1728.04.13, AHPCO, PNMO, Leg. 7358P, f. 43v).

${ }^{88} \mathrm{Y}$ valorados respectivamente en 4 reales (1728.04.13, AHPCO, PNMO, Leg. 7358P, f. 43v).

${ }^{89}$ Unas tijeras, una azuela, dos barrenas, un escoplo, una sierra y un mazo de hierro se mencionan en el instrumental del batán de la parada de Cucarrón (1497.12.28, AHPCO, PNCO, Leg. 14136P, Cuad. 16, f. 10v); cuatro pares de tijeras, aserrón, sierra y azuela, barrenas y compás, porra y barra de hierro, mazo de madera en el del batán de la Hoz (1728.04.13, AHPCO, PNMO, Leg. 7358P, f. 43v). 
de elementos que hicieron posible la realización del trabajo en el interior del batán ${ }^{90}$. $\mathrm{Al}$ fin todos estos elementos jugaron un papel tan trascendental en el abatanado de los paños como el propio batán, dado que sin ellos difícilmente podría haberse llevado a cabo ésta, ni ninguna otra, actividad laboral.

En suma, a través de los datos documentales conservados, hemos intentado poner de relieve cómo eran los batanes de la cuenca del Guadalquivir a fines de la Edad Media, alcanzando una conclusión que en apariencia puede resultar insignificante, la de que dichos batanes fueron similares -en sus piezas, componentes, funcionamiento y sistemas de explotación-, a los batanes históricos conocidos en época más moderna y a los ejemplares que, habiendo llegado al siglo XX, han sido estudiados desde el punto de vista etnográfico en distintas regiones peninsulares. Sin embargo, esta conclusión aporta una certeza relevante para la historia de la técnica, a saber, la de que los batanes del Guadalquivir ya eran, en el siglo XV, similares -en sus piezas, componentes, funcionamiento y sistemas de explotación-, a los que se mantuvieron en funcionamiento en la Península hasta los siglos XIX y XX. Ello evidencia que el batán hidráulico alcanzó en época medieval los rasgos técnicos que perduraron durante los siguientes siglos, que la tecnología industrial de los últimos siglos medievales estuvo a la altura del desarrollo alcanzado -al menos en casos concretos, como el que nos ocupa- en los siglos de la Modernidad y que las soluciones técnicas diseñadas por los aladreros medievales mantuvieron su validez a lo largo de mucho tiempo. De hecho, su desaparición, como la de los propios molinos harineros hidráulicos, vino más dictada por el uso de nuevas fuentes de energía que por la superación del sistema de trabajo y de aprovechamiento hidráulico que el batán tradicional representaba.

\section{BIBLIOGRAFÍA CITADA}

Alegría Suescun, David, Molino y batán de Villava-Atarrabia: nueve siglos de Historia, Pamplona, Consorcio del Parque Fluvial, 2006.

Alfaro, Carmen, Tejido y cestería en la Península Ibérica, Madrid, Instituto Español de Prehistoria, 1984, pp. 225-227.

Alonso, Luis Antonio, La pisa de Ledantes, "Cantabria Infinita” 10 (2008), pp. 12-18.

Argemí, Mercè; Barceló, Miquel; Cressier, Patrice; Kirchner, Helena; Navarro, Carmen, Glosario de términos hidráulicos, en El agua en la agricultura de alAndalus, Barcelona, El Legado Andalusí, 1995, pp. 163-189.

Bautier, Anne Marie, Les plus anciens mentions de moulins hydrauliques industriels et de moulins à vent, "Bulletin Philologique et Historique" 2 (1960), pp. 567-626.

Bejarano, Amparo; Molina, Antonio Luís, Las ordenanzas municipales de Chinchilla en el siglo XV, Murcia, Academia Alfonso X el Sabio, 1989.

Bernat i Roca, Margalida, Aeris salubritate. Neteja i higiene pública a Ciutat de Mallorca (s. XIV-XVII), "Butlletí de la Societat Arqueológica Lul-liana" 50 (1994), pp. 253-286.

Bernat i Roca, Margalida, Els "III Mesters de la Llana”. Paraires, teixidors de llana $i$ tintorers a Ciutat de Mallorca (s. XIV-XVII), Palma de Mallorca, Institut d'Estudis Baleàrics, 1995.

\footnotetext{
${ }^{90}$ Ocho banquetas y dos mesas, 18 reales; las puertas de la casa, 40; un pedazo de cadena y 151 eslabones de cadena, 15; cuatro mangos y un harnero, 7; una sartén, 8; tres candiles, 3; el sombrajo armado, 6 (1728.04.13, AHPCO, PNMO, Leg. 7358P, f. 43v).
} 
Bernat i Roca, Margalida, Los batanes de Ciutat de Mallorca (siglos XIII-XVII), en $7^{\circ}$ Congreso Internacional de Molinología, Zamora, Universidad de Salamanca, 2010, pp. 406-415.

Bernat i Roca, Margalida, Molins drapers a Ciutat de Mallorca: entre interessos politics i econòmics, "Estudis Baleàrics" 58-59 (1987), pp. 127-150.

Bonnassie, Pierre, La organización del trabajo en Barcelona a fines del siglo XV, Barcelona, Universidad - Instituto de Historia Medieval de España, 1975.

Bordes García, José, Desarrollo industrial textil y artesanado en Valencia de la conquista a la crisis (1238-1350), Valencia, Bancaja, 2006.

Braojos, Luis Antonio, Explotación y comercio de la greda en Magán, Toledo: datos históricos y arqueológicos, en I Congreso de Historia de Castilla La Mancha, Ciudad Real, Junta de Comunidades de Castilla La Mancha, 1988, vol. VI, pp. 119-126.

Cabrera Sánchez M., Oligarquía y negocio inmobiliario en Córdoba en la segunda mitad del siglo XV, "Historia. Instituciones. Documentos" 20 (1993), pp. 107-126.

Caro Baroja, Julio, Tecnología Popular Española, Madrid, Editora Nacional, 1983.

Carus-Wilson, Eleanor, An Industrial Revolution of the Thirteenth Century, "Economic History Review" 11 (1941), pp. 39-60.

Carvalho Quintela, Antonio de, Engenhos hidráulicos em Portugal. Finalidades, tipos e difusao. Características das rodas hidráulicas, en Primeras Jornadas Nacionales sobre Molinología, Santiago, Edicios do Castro, 1997, pp. 19-38.

Clarke, Henry, The Archaeology of Medieval England, Oxford, Blackwell, 1986.

Crowfoot, Elisabeth; Pritchard, Frances; Staniland, Kay, Textiles and Clothing 11501450. Medieval Finds from Excavations in London 4, Londres, Museum of London, 1992.

Córdoba, Ricardo, Aceñas y batanes de la Iglesia de Córdoba a fines del siglo XV, en F. Toro, A. Linaje (eds.), Iglesias y fronteras: V Jornadas de Historia en la Abadia, Jaén, Diputación, 2005, pp. 113-126.

Córdoba, Ricardo, Influencia orientales en la artesanía andaluza de la Baja Edad Media, en Andalucía entre Oriente y Occidente 1236-1492 (E. Cabrera, ed.), Córdoba, Diputación, 1988, pp. 585-598.

Córdoba, Ricardo, Innovación tecnológica y desarrollo industrial en la Península Ibérica durante la Edad Media, en Actas de las I Jornadas sobre Minería y Tecnología en la Edad Media peninsular, Madrid, Fundación Hullera Vasco-leonesa, 1996, pp. 317-346.

Córdoba, Ricardo, Intervención arqueológica de apoyo a la restauración en un edificio industrial: el molino de la Alegría (Córdoba), en V Congreso de Arqueología Medieval Española, Valladolid, Junta de Castilla y León, 2001, vol. I, pp. 361-369

Córdoba, Ricardo, La actividad industrial en una localidad de frontera: Castro del Río entre la Edad Media y los tiempos modernos (1480-1530), en F. Toro, J. Rodríguez Molina, (eds.), II Estudios de Frontera. Actividad y vida en la frontera, Jaén, Diputación, 1998, pp. 191-216.

Córdoba, Ricardo, La industria medieval de Córdoba, Córdoba, Caja Provincial, 1990.

Córdoba, Ricardo, Las técnicas pre-industriales, en L. García-Ballester (ed.), Historia de la Ciencia y de la Técnica en la Corona de Castilla II: Edad Media, Valladolid, Junta de Castilla y León, 2002, pp. 221-432.

Córdoba, Ricardo, Los molinos del Puente de Córdoba. Estado actual y propuestas de actuación, en I Jornadas Nacionales sobre Molinología, La Coruña, Edicios do Castro, 1997, pp. 91-104. 
Córdoba, Ricardo, Los molinos hidráulicos de la cuenca del Guadalquivir a fines de la Edad Media. Instrumental y equipamiento técnico, "Anuario de Estudios Medievales" 33/1 (2003), pp. 291-337.

Córdoba, Ricardo, Molinos y batanes de la Córdoba medieval, "Ifigea. Revista de la Sección de Geografía e Historia" 9 (1993), pp. 31-56.

Córdoba, Ricardo, Some Reflections on the Use of Water Power in al-Andalus, en S. Cavaciocchi (ed.), Economia ed Energia, secc. XIII-XVIII, Florencia, Le Monnier, 2003, pp. 931-954

Córdoba, Ricardo; Albendín, A.; García, J.M; Ortiz, J., Puertos, azudas y norias. El patrimonio hidráulico histórico de Palma del Río (Córdoba), Sevilla, Fundación El Monte, 2004.

Córdoba, Ricardo; Cuenca Montilla, Juan; Hernández Íñigo, Pilar; Ortiz García, José, Los molinos hidráulicos del Guadalquivir en la ciudad de Córdoba. Estudio histórico y arquitectónico, Madrid, CEHOPU, 2008.

Córdoba, Ricardo; Varela, Juan, El Patrimonio Histórico Hidráulico de la cuenca del Guadajoz. Estudio y Catalogación, "Salsum. Monografías del Museo Histórico Municipal” 2, Baena, Ayuntamiento de Baena - Diputación de Córdoba, 2011.

Cortés Vázquez, Luís, El batán de La Horcajada, “Zephyrus” 7 (1956), pp. 21-31.

Daumas, Maurice, Les origines de la civilisation technique, París, PUF, 1962.

Díaz Gómez, Alberto; Sopeña Pérez, Fernando, El batán o pisa de Ledantes, "Publicaciones del Instituto de Etnografía y Folklore Hoyos Sainz" 8 (1976), pp. 277-294.

Endrei, Walter, Changements dans la productivité de l'industrie lainière au Moyen Age, en M. Spallanzani (ed.), Produzione, commercio e consumo dei panni di lana (sec. XII-XVIII), Florencia, Leo S. Olschki, 1976, pp. 625-632.

García Manso, Emilio, La terminología medieval respecto a la tipología, función y tamaño de las instalaciones molineras, en Actas de las II Jornadas de Molinología, Lleida, Institut d'Estudis Ilerdencs, 1999.

García Tapia, Nicolás, Técnica y poder en Castilla durante los siglos XVI y XVII, Salamanca, Junta de Castilla y León, 1989.

Gimpel, Jean, La revolución industrial de la Edad Media, Barcelona, Taurus, 1982.

González Arce, José Damián, La industria de Chinchilla en el siglo XV, Albacete, Instituto de Estudios Albacetenses, 1993.

González Tascón, Ignacio, Fábricas Hidráulicas Españolas, Madrid, CEHOPU, 1986.

Gual Camarena, Miguel, Orígenes y expansión de la industria textil catalana, en M. Spallanzani (ed.), Produzione, Commercio e Consumo dei panni di lana (secc. XII-XVIII), Florencia, Leo S. Olschki, 1976, pp. 511-523.

Iradiel, Paulino, Evolución de la industria textil castellana en los siglos XIII al XVI, Salamanca, Universidad, 1974.

Iradiel, Paulino; Igual, David; Navarro, Germán; Aparici, José, Oficios artesanales y comercio en Castelló de la Plana (1371-1527), Castellón, Fundación Dávalos-Fletcher, 1995.

Lennard, Reginald V., An Early Fulling-Mill: a note, "Economic History Review" 17 (1947), p. 150

Lennard, Reginald V., Early English Fulling Mills: additional examples, "Economic History Review" 21 (1951), pp. 342-343.

Malanima, Paolo, The first European textile machine, "Textile History" 17 (1986), pp. 115-127.

Martínez, María, La industria del vestido en Murcia (siglos XIII-XV), Murcia, Academia Alfonso X el Sabio, 1988

Morís, Gonzalo, Ingenios hidráulicos históricos: molinos, batanes y ferrerías, "Ingeniería del Agua" 2 (1995), pp. 25-42. 
Morís, Gonzalo, Molinos y batanes, en Enciclopedia de la Asturias Popular, Oviedo, La Voz de Asturias, 1994, vol. I, pp. 193-208.

Munro, John Henry, Industrial Energy from Water-mills in the European Economy, $5^{\text {th }}$ to $18^{\text {th }}$ centuries: the limitations of power, en S. Cavaciocchi (ed.), Economia ed Energia, secc. XIII-XVIII, Florencia, Le Monnier, 2003, pp. 223-269.

Munro, John Henry, Textile Technology in the Middle Ages, en Textiles, Towns and Trade. Essays in the economic history of late-medieval England and the Low Countries, Aldershot, Ashgate Variorum, 1994.

Ortiz García, José, Transformación arquitectónica del conjunto monumental de la parada de Martos en Córdoba: la realización de la obra del batán durante el siglo XVI, en IV Congrès Internacional de Molinología, Palma de Mallorca, Consell de Mallorca, 2005, pp. 229-238.

Padilla Lapuente, José Ignacio, La construcció d'un enginy hidràulic: els comptes del molí batà de Gardeny (Lleida, 1290-91), "Ilerda" 49/2 (1991), pp. 105-128.

Pallaruelo, Severino, Los molinos del Altoaragón, Huesca, Instituto de Estudios Altoaragoneses, 1994.

Quintanilla, Concepción, Villafranca, una encomienda calatrava en el reino de Córdoba, "Historia. Instituciones. Documentos" 6 (1979), pp. 281-308.

Reyes Téllez, Francisco; Gil Pulido, José Ignacio; Menéndez Robles, Ma Luisa, Organización del espacio y comercio de la greda en Magán (Toledo), en Arqueología Espacial. Coloquio sobre el microespacio 4, Teruel, Diputación Provincial, 1986, pp. 191-203.

Reynolds, T. S., Stronger than a hundred men. A history of the vertical water-wheel, Baltimore, The John Hopkins University Press, 1988.

Sáez, Emilio, Colección documental del archivo de la catedral de León, León, 1987.

Sánchez Ferrer, José, Los batanes lagunares de Ossa de Montiel, "Al-Basit. Revista de Estudios Albacetenses" 23 (1988), pp. 101-130.

Sánchez Ferrer, José, Noticias documentales para el estudio y la localización de los batanes de la provincia de Albacete, "Al-Basit. Revista de Estudios Albacetenses" 26 (1990), pp. 27-79.

Uscatescu, A., En torno a la tendícula de Séneca (Quaest. Nat. 1, 3, 2): una aproximación léxica e iconográfica a la ars fullonia, "Archivo Español de Arqueología" 83 (2010), pp. 203-220.

Uscatescu, A., Fvllonicae et Tinctoriae en el mundo romano, Barcelona, PPU, 1994.

Utrilla, Juan Francisco, Los orígenes de la industria textil en Huesca: la construcción de los primeros molinos traperos (c. 1180-1190) y la creación de la cofradía de los tejedores oscenses (1239), en Homenaje a Don Antonio Durán Gudiol, Huesca, Instituto de Estudios Altoaragoneses, 1995, pp. 805-816.

Vázquez-Varela, José Manuel; Villarino Pérez, Montserrat; Cabana González, Marina, Batanes de Mosquetín, La Coruña, Diputación, 1999.

Veiga de Oliveira, Ernesto; Galhano, Fernando, Tecnologia Tradicional. Pisoes Portugueses, Lisboa, Instituto Nacional de Investigaçao Científica, 1977.

White, K.D., Greek and Roman Technology, Londres, Cornell, 1984.

White, Lynn, Tecnología medieval y cambio social, Barcelona, Paidós, 1990.

Fecha de recepción del artículo: agosto 2011

Fecha de aceptación y versión final: octubre 2011 